\title{
A Nonpolar Blueberry Fraction Blunts NADPH Oxidase Activation in Neuronal Cells Exposed to Tumor Necrosis Factor- $\alpha$
}

\author{
Sally J. Gustafson, ${ }^{1}$ Kriya L. Dunlap, ${ }^{1}$ Colin M. McGill,, ${ }^{1,2}$ and Thomas B. Kuhn' \\ ${ }^{1}$ Department of Chemistry and Biochemistry, University of Alaska Fairbanks, 900 Yukon Drive, REIC 194, Fairbanks, \\ AK 99775, USA \\ ${ }^{2}$ Chemistry Department, University of Alaska Anchorage, Anchorage, AK 99508, USA
}

Correspondence should be addressed to Thomas B. Kuhn, tbkuhn@alaska.edu

Received 25 May 2011; Revised 16 September 2011; Accepted 11 November 2011

Academic Editor: Qingping Feng

Copyright (C) 2012 Sally J. Gustafson et al. This is an open access article distributed under the Creative Commons Attribution License, which permits unrestricted use, distribution, and reproduction in any medium, provided the original work is properly cited.

Inflammation and oxidative stress are key to the progressive neuronal degeneration common to chronic pathologies, traumatic injuries, and aging processes in the CNS. The proinflammatory cytokine tumor necrosis factor-alpha (TNF- $\alpha$ ) orchestrates cellular stress by stimulating the production and release of neurotoxic mediators including reactive oxygen species (ROS). NADPH oxidases (NOX), ubiquitously expressed in all cells, have recently emerged as pivotal ROS sources in aging and disease. We demonstrated the presence of potent NOX inhibitors in wild Alaska bog blueberries partitioning discretely into a nonpolar fraction with minimal antioxidant capacity and largely devoid of polyphenols. Incubation of SH-SY5Y human neuroblastoma cells with nonpolar blueberry fractions obstructed the coalescing of lipid rafts into large domains disrupting NOX assembly therein and abolishing ROS production characteristic for TNF- $\alpha$ exposure. These findings illuminate nutrition-derived lipid raft modulation as a novel therapeutic approach to blunt inflammatory and oxidative stress in the aging or diseased CNS.

\section{Introduction}

Persistent inflammation and oxidative stress is largely accountable for the progressive degeneration of neuronal connectivity and neurons ultimately contributing to cognitive decline associated with many CNS pathologies and aging processes [1]. Intensive research supports the emerging potential of nutrition in particular fruits and vegetables, as an epigenetic measure to retard, halt, or even prevent neurodegeneration and cognitive decline associated with aging and disease [2-4]. A diet rich in blueberries improved memory, learning, and motor skills of aging animals and reduced markers of inflammatory and oxidative stress [5-8]. Blueberry supplementation provided considerable neuroprotection in an ischemia model greatly reducing neuronal loss [9]. Krikorian and colleagues demonstrated in human subjects a substantial improvement of verbal memory tasks after blueberry juice consumption [10]. Although many of the benefits of blueberries and other foods were correlated to polyphenolics and their inherent high antioxidant capacities, recent findings provided convincing evidence that health benefits of phytochemicals reach far beyond and include specific modulation of biochemical mechanisms and associated cellular targets [11-16].

The proinflammatory cytokine tumor necrosis factoralpha $(\mathrm{TNF} \alpha)$ is key to orchestrating inflammatory and oxidative stress in the CNS $[17,18]$. In various cell types including neurons, TNF $\alpha$ stimulates a rapid accumulation of the neurotoxic lipid messenger ceramide and a massive overproduction of reactive oxygen species (ROS), primarily through NADPH oxidase (NOX) activities [19-21]. The prototypical NOX isoform is a multisubunit protein complexes composed of two membrane subunits (NOX 1-3 and gp22 phox), at least three cytosolic subunits ( $\mathrm{p} 67^{\text {phox }}, \mathrm{p} 47^{\text {phox }}$, and $\mathrm{p} 40^{\mathrm{phox}}$ ), and the regulatory small GTPase Rac1 or Rac2 [22, 23]. These NOX isoforms generate ROS via an intricate assembly between the cytosolic and membrane subunits at the plasma membrane in conjunction with lipid activators such as ceramide metabolites and arachidonic acid [24, 25]. Only recently have members of the NOX family (homologous of plasma membrane protein $\mathrm{gp} 91^{\text {phox }}$ ) emerged as pivotal sources of oxidative stress in a plethora of chronic diseases and aging 
responsible for oxidative damage to proteins, lipids, and nucleic acids [26-28]. Regardless, current pharmacology against NOX activities either lacks specificity or is highly cytotoxic [29]. In lieu of the demonstrated antioxidant and anti-inflammatory properties of blueberries, we hypothesized that wild Alaska bog blueberries might possess the capability to blunt NOX activities. Previously, we demonstrated that SH-SY5Y human neuroblastoma cells responded to $\mathrm{TNF} \alpha$ exposure with a rapid increase in intracellular superoxide generated by NOX2. This ROS response required prior activation of a $\mathrm{Mg}^{2+}$-dependent neutral sphingomyelinase and ceramide generation [30]. Utilizing this cellular model of neuroinflammation as our bioassay, we set out to determine (i) whether wild Alaska bog blueberries contained NOX inhibitory potency at all, and (ii) to potentially enrich this potency. Due to the presence of multiple ROS sources in cells, we assessed NOX activity not only by measuring ROS generation but also quantifying the translocation to and increased association of the cytosolic p67phox subunit with neuronal plasma membranes. Indeed, incubation of $\mathrm{SH}$ SY5Y human neuroblastoma cells with crude blueberry extracts abolished NOX-mediated ROS production upon exposure to TNF $\alpha$. This NOX inhibiting bioactivity in crude blueberry extracts partitioned into a polyphenol-devoid fraction lacking virtually any antioxidant capacity, and prevented proper assembly of the multisubunit NOX complex. Moreover, this nonpolar and non-antioxidant NOX-inhibiting bioactivity interfered with the coalescence of large lipid raft domains typically observed in SH-SY5Y cells exposed to TNF $\alpha$. These findings demonstrate the presence of natural products in wild Alaska bog blueberries, and likely other phytosources, as novel NOX inhibitors and support for a potential nutrition-derived epigenetic therapy to confine or blunt inflammatory and oxidative stress in the aging or diseased CNS.

\section{Methods and Materials}

2.1. Reagents. DMEM and penicillin/streptomycin solution were obtained from Mediatech (Herndon, VA). GlutaMAX1, trypsin/EDTA solution, 3, 3', 5, 5'-tetramethylbenzidine (TMB), 2', $7^{\prime}$-dihydrodicholorfluorecein diacetate $\left(\mathrm{H}_{2} \mathrm{DCFDA}\right)$, Alexa Fluor 555 Lipid Raft labeling kit, and NuPAGE running and transfer buffers were purchased from Invitrogen (Carlsbad, CA). 3-(4,5-dimethylthiazol-2-yl)-2, 5-diphenyl tetrazolium bromide (MTT) Cell Growth assay kit was from Millipore (Temecula, CA). Primary antip67phox and antiphospho p40 phox antibodies were obtained from Abcam (Cambridge, MA) and Santa Cruz Biotechnology (Santa Cruz, CA), respectively. BCA Protein assay kit and 1-step NBT/BCIP were from Pierce (Rockford, IL). Fetal bovine serum was received from Atlanta Biologicals (Atlanta, GA). Recombinant human TNF $\alpha$ was received from ProSpec (Rehovot, Israel), and PMA was from Biomol (Plymouth, PA). All other reagents were purchased from Sigma Aldrich (St. Louis, MO).

2.2. Cell Culture. SH-SY5Y human neuroblastoma cells were grown in DMEM medium supplemented with $10 \%$ fetal bovine serum, $100 \mathrm{U} / \mathrm{mL}$ penicillin, $100 \mathrm{U} / \mathrm{mL}$ streptomycin, and 1\% GlutaMax-1, (humidified atmosphere, $5 \% \mathrm{CO}_{2}, 37^{\circ} \mathrm{C}$ ) in $100 \mathrm{~mm}$ dishes (Falcon). For amplification, SH-SY5Y cells were incubated with trypsin $(0.5 \mathrm{mg} / \mathrm{mL}) /$ EDTA $(0.2 \mathrm{mg} / \mathrm{mL})$ in PBS, washed off, briefly triturated, and replated (1:3 dilution) in $100 \mathrm{~mm}$ dishes (Falcon). For experiments, SH-SY5Y cells were harvested after trypsin/EDTA treatment, triturated, and plated onto poly-D-lysine-coated glass cover slips inserted in $35 \mathrm{~mm}$ dishes (confocal microscopy) or on to tissue culture treated 6-well or 96-well plates. Cells were grown for 24 hours to $40 \%$ (confocal microscopy) or $80 \%$ confluency (biochemical assays), and serum starved overnight in DMEM, 1\% GlutaMax-1, $100 \mathrm{U} / \mathrm{mL}$ penicillin, and $100 \mathrm{U} / \mathrm{mL}$ streptomycin (humidified atmosphere, $5 \% \mathrm{CO}_{2}, 37^{\circ} \mathrm{C}$ ) prior to assays.

2.3. Blueberry Extract Preparation. Alaska Wild Bog Blueberries (Vaccinium uliginosum) were harvested in the vicinity of Fairbanks, AK, and stored frozen $\left(-20^{\circ} \mathrm{C}\right)$. Next, blueberries were lyophilized and crushed to a powder. Approximately $20 \mathrm{~g}$ of blueberry powder was fractionated over a silica column in $500 \mathrm{~mL}$ fractions with a mobile phase of $80 / 20$ dichloromethane/methanol. Fractions were filtered, rotovaporized at $40^{\circ} \mathrm{C}$ to remove volatile organics, frozen, and then lyophilized again. The powder extracts were stored at $-20^{\circ} \mathrm{C}$ until reconstituted immediately prior to use in a 70:30 acetone-water solution, and diluted $1: 20$ into deionized (18 mega $\Omega$ ) water as our stock solutions of nonpolar and polar blueberry fractions. Final assay concentration of $5 \mu \mathrm{g} / \mathrm{mL}$ of crude extracts or fractions exhibited full potency with no apparent cytotoxicity. Considering that only $10-12 \%$ of blueberries account as dry weight, $5 \mu \mathrm{g} / \mathrm{mL}$ in $10 \mathrm{~mL}$ of medium equates to $0.4-0.5 \mathrm{mg}$ wet weight or approximately 5 whole berries or less.

2.4. Quantification of Reactive Oxygen Species Production. SH-SY5Y cells were grown in 6-well plates, serum starved overnight, and then loaded with $1 \mu \mathrm{M} \mathrm{H}_{2} \mathrm{DCFDA}\left(1 \mathrm{~h}, 37^{\circ} \mathrm{C}\right)$ in the presence or absence of $10 \mu \mathrm{M}$ diphenyl iodonium (DPI), $1 \mathrm{mM} \mathrm{N}$-acetyl-L-cysteine (NAC), $1 \mathrm{mM} \mathrm{4-}$ (2-aminoethyl) benzenesulfonyl fluoride (AEBSF), $13.8 \mu \mathrm{M}$ GW4896, or $5 \mu \mathrm{g} / \mathrm{mL}$ nonpolar or polar blueberry fractions. After washing with serum-free medium, SH-SY5Y cells were exposed to $200 \mathrm{ng} / \mathrm{mL} \mathrm{TNF} \alpha, 400 \mathrm{ng} / \mathrm{mL}$ PMA (phorbol-12myristate 13-acetate ester), or vehicle in serum-free medium $(1 \mathrm{~h})$, washed with PBS, and lysed ( $2 \mathrm{M}$ Tris- $\mathrm{Cl} \mathrm{pH} \mathrm{8.0,2 \%}$ SDS, $10 \mathrm{nM} \mathrm{Na}_{3} \mathrm{VO}_{4}$ ). Lysates were cleared by centrifugation, $100 \mu \mathrm{L}$ aliquots were transferred to black 96-well plates (Falcon), and total DCF fluorescence intensity was quantified using a Beckman Coulter Multimode DTX 880 microplate reader ( $495 \mathrm{~nm}$ excitation filter, 525 emission filter). All data were adjusted to total protein concentration (BCA assay) and normalized to control condition to account for unspecific fluorescence and/or autofluorescence artifacts.

2.5. Choline Oxidase Assay. Addition of choline to a mixture of choline oxidase, horseradish peroxidase, and Amplex Red generates hydrogen peroxide and subsequently the formation 
of the fluorescent product resorufin. To assay for hydrogen peroxide scavenging, blueberry fractions at $5 \mu \mathrm{g} / \mathrm{mL}$ or $75 \mu \mathrm{g} / \mathrm{mL}$, catalase $(2000 \mathrm{U} / \mathrm{mL})$, or vehicle were added to the above reaction mixture, incubated for $15 \mathrm{~min}$, and then supplemented with $50 \mu \mathrm{M}$ choline for $15 \mathrm{~min}$ at $37^{\circ} \mathrm{C}$. Resorufin fluorescence was measured at $590 \mathrm{~nm}$ using a Beckman Coulter Multimode DTX 880 microplate reader.

2.6. Cytotoxicity Assay. Cell viability was determined using a MTT assay according to manufacturer's instructions (Millipore). Briefly, serum-starved SH-SY5Y cells were incubated with increasing amounts of blueberry fractions $(5,30$, or $75 \mu \mathrm{g} / \mathrm{mL}$ ) or $\mathrm{H}_{2} \mathrm{O}_{2}$ and incubated for $48 \mathrm{~h}$. Cultures were washed and incubated with MTT. Generation of insoluble formazan generation was measured using a Beckman Coulter Multimode DTX 880 microplate reader.

2.7. Cytochrome C Reduction Assay. Superoxide production was measured as cytochrome $\mathrm{C}$ reduction sensitive to $\mathrm{SOD}$ inhibition as detailed in $\mathrm{Li}$ and Shah with minor modifications [31, 32]. SH-SY5Y cells grown in 6-well plates to $90 \%$ confluency were serum-starved overnight, incubated with pharmacological inhibitors (10 mM DPI, $2 \mathrm{mM} \mathrm{AEBSF}$, $2 \mathrm{mM} \mathrm{NAC})$, or blueberry fractions $(5 \mu \mathrm{g} / \mathrm{mL}, 1 \mathrm{~h})$, and then exposed to TNF $\alpha(200 \mathrm{ng} / \mathrm{mL})$ for $30 \mathrm{~min}$. SH-SY5Y cells were harvested in Hank's balanced salt solution, lysed by sonication, and centrifuged $\left(1000 \times \mathrm{g}_{\max }, 5 \mathrm{~min}\right)$ to removed nuclei and intact cells. Aliquots were removed to determine total protein concentration (BCA assay). Lysates $(150 \mu \mathrm{L})$ were supplemented with $10 \mu \mathrm{M}$ FAD, $200 \mu \mathrm{M}$ NADPH, and $100 \mu \mathrm{M}$ cytochrome $\mathrm{C}$ and either $200 \mathrm{U} / \mathrm{mL}$ SOD or vehicle (total volume $200 \mu \mathrm{L}$ ), and absorbance at $550 \mathrm{~nm}$ was measured using a Beckman Coulter Multimode DTX 880 microplate reader. All measurements were adjusted to total protein concentration and normalized to control conditions.

2.8. ELISA Assay for P67 $7^{\text {phox }}$ and Phosphor P40 $0^{\text {phox }}$ SH-SY5Y cells grown in $100 \mathrm{~mm}$ dishes to $80 \%$ confluency were serumstarved overnight, incubated in the presence or absence of blueberry fractions $(5 \mu \mathrm{g} / \mathrm{mL}, 1 \mathrm{~h})$, and then stimulated $(1 \mathrm{~h})$ with TNF $\alpha(200 \mathrm{ng} / \mathrm{mL})$ or PMA $(400 \mathrm{ng} / \mathrm{mL})$. SH-SY5Y cells were harvested and lysed (sonication) in a $0.33 \mathrm{M}$ sucrose buffer (20 mM Tris-HCL pH 8.0, 2 mM EDTA, 0.5 EGTA, $2 \mathrm{mM}$ AEBSF, $25 \mu \mathrm{g} / \mathrm{mL}$ Leupeptin), and centrifuged $\left(25,000 \times \mathrm{g}_{\max }, 15 \mathrm{~min}\right)$. Supernatants (cytosolic fraction) were removed and pellets were resuspended in $20 \mathrm{mM}$ TrisHCL pH 8.0, 2 mM EDTA, 0.5 mM EGTA, and 2 mM AEBSF. After centrifugation $\left(25,000 \times \mathrm{g}_{\max }, 15 \mathrm{~min}\right)$, supernatants were collected (membrane fraction) and aliquots were removed to determine total protein concentration (BCA assay). Next, 96-well high protein absorbent plates (Falcon) were incubated with $20 \mu \mathrm{g} / \mathrm{mL}$ of total membrane protein in TBST $\left(12 \mathrm{~h}, 25^{\circ} \mathrm{C}\right)$. After blocking with $5 \% \mathrm{w} / \mathrm{v}$ BSA in TBST $(1 \mathrm{~h})$, wells were incubated with rabbit antip67phox or phospho $440^{\text {phox }}$ polyclonal antibodies $(3 \mu \mathrm{g} / \mathrm{mL}$, $4^{\circ} \mathrm{C}$, overnight), rinsed with TBST, and incubated with a secondary goat anti-rabbit IgG antibody conjugated to HRP $\left(1: 2000,45 \mathrm{~min}, 25^{\circ} \mathrm{C}\right)$. After a wash step (TBST), $100 \mu \mathrm{L}$
TMB (tetramethylbenzidine) was added and absorbance at $620 \mathrm{~nm}$ measured 10 min later using a Beckman Coulter Multimode DTX 880 microplate reader.

2.9. Gel Electrophoresis and Western Blotting. Equal amounts of total protein $(5 \mu \mathrm{g})$ were loaded onto a $10 \%$ SDS-polyacrylamide gel and separated $(125 \mathrm{~V}, 50 \mathrm{~W}, 40 \mathrm{~mA})$ using NuPAGE MES running buffer. Proteins were transferred onto nitrocellulose membranes $(100 \mathrm{~V}, 350 \mathrm{~mA}, 50 \mathrm{~W}, 1 \mathrm{hr})$ using NuPAGE transfer buffer and then blocked $(1 \mathrm{~h})$ with $5 \% \mathrm{w} / \mathrm{v}$ BSA in TBST. Membranes were incubated overnight with a goat anti-p67 ${ }^{\text {phox }}$ antibody $\left(1: 500\right.$ in TBST, $\left.4^{\circ} \mathrm{C}\right)$, washed with TBST, and then incubated with the corresponding secondary antibody conjugated to alkaline phosphatase ( $1: 5000$ in TBST, $1 \mathrm{~h}, \mathrm{RT})$. Immunoreactivity was detected by colorimetric detection using NBT/BCIP.

2.10. Confocal Microscopy. SH-SY5Y cells grown on poly-Dlysine-coated glass cover slips ( $0.13 \mathrm{~mm}$ thick German glass) were serum starved overnight. Cultures were incubated $(1 \mathrm{~h})$ with blueberry fractions $(5 \mu \mathrm{g} / \mathrm{mL})$ prior to addition of TNF $\alpha$ $(200 \mathrm{ng} / \mathrm{mL})$ or PMA $(400 \mathrm{ng} / \mathrm{mL})$. Cultures were labeled with Alexa Fluor Lipid Raft Labeling kit 555 (Invitrogen) according to manufactures instructions. After fixation with $4 \%$ paraformaldehyde $\left(20 \mathrm{~min}, 4^{\circ} \mathrm{C}\right)$, cells were permeabilized with $0.3 \%$ Triton-X-100 in PBS $\left(20 \mathrm{~min}, 4^{\circ} \mathrm{C}\right)$ and then blocked with $1 \%$ normal goat serum in PBS. Cultures were incubated with rabbit anti-p67 $7^{\text {phox }}$ antibody $(1: 200$, overnight, $4^{\circ} \mathrm{C}$ ) in $0.1 \%$ TX-PBS, washed (PBS), and incubated with secondary FITC-conjugated goat-anti-rabbit antibody $(1: 200,2 \mathrm{~h}, \mathrm{RT})$. After rinsing (TBS), cover slips were mounted with PVA-DABCO (overnight, RT), and stored at $4^{\circ} \mathrm{C}$ until inspection. Images were acquired $(63 \mathrm{x}$, oil, Plan Fluor) with a Zeiss confocal microscope LSM 510 equipped with a $\mathrm{He} / \mathrm{Ne}$ laser and an Argon laser using filter combinations for Alexa 555 (554 excitation, 570 emission) and FITC (494 excitation, 517 emission). Zeiss LSM Software was used for image acquisition and analysis. For each treatment condition, random fields of view were used to analyze 3 cells from two independent sets of experiments $(n=6)$.

2.11. Statistical Analysis. Significant differences between treatments and within multiple groups $\left({ }^{*} P<0.05\right)$ were calculated using analysis of variance (ANOVA) followed by Tukey's post hoc analyses using Statistical Analysis System (SAS) software. Data were collected from at least four independent experiments and are presented as mean \pm standard deviation unless indicated otherwise.

\section{Results}

Utilizing human SH-SY5Y neuroblastoma cells exposed to TNF $\alpha$ or PMA as a cellular model of neuroinflammation, we investigated whether crude extracts obtained from wild Alaska bog blueberries (AK-BB) harbor the potential to blunt NOX activity by disrupting the protein subunit assembly rather than scavenging ROS. Previous studies in SH-SY5Y cells revealed that TNF $\alpha$ elicited superoxide generation through NOX2 activation derived from quantitative analyses 
using the superoxide-specific fluorescence indicator dihydroethidium in combination with the peroxide-sensitive fluorescence indicator DCF [21]. In the following studies we relied on DCF measurements in lieu of the cytotoxicity of dihydroethidium and potential concentration-dependent artifacts.

\subsection{A Nonpolar Blueberry Fraction Blunts NOX-Mediate ROS} Formation in Neuronal Cells Exposed to TNFa or PMA. SH-SY5Y cells were incubated either with pharmacological inhibitors, crude blueberry extract, or blueberry fractions prior to exposure to $200 \mathrm{ng} / \mathrm{mL}$ TNF $\alpha$ or $400 \mathrm{ng} / \mathrm{mL}$ PMA. Increases in ROS were quantified using the oxidation sensitive fluorescence indicator DCF due to minimal cytotoxicity. All data was adjusted to total cellular protein and normalized to control conditions to account for unspecific fluorescence. Pretreatment of SH-SY5Y cells with $5 \mu \mathrm{g} / \mathrm{mL}$ AK-BB extracts diminished TNF $\alpha$-mediated ROS formation $(1.06 \pm 0.06, n=$ $4)$ to control levels $(1.00 \pm 0.25, n=4)$ and AK-BB extracts did not alter basal levels of ROS formation in SHSY5Y cells $(0.96 \pm 0.1, n=4)$. As expected, TNF $\alpha$ in the absence of AK-BB extracts $(1.85 \pm 0.25, n=4, * P<$ 0.05 ) evoked significant ROS formation (Figure 1(a)). Next, AK-BB extracts were fractionated according to increasing polarity with polyphenolics concentrating in the most polar fractions (see inset Figure 1(b)). Using a bioassay approach, each fraction was tested for its capacity to negate TNF $\alpha$ mediated ROS formation. As shown in Figure 1(b), the most nonpolar fraction ( $\mathrm{NP}_{\mathrm{BB}}$, colorless) at $5 \mu \mathrm{g} / \mathrm{mL}$ potently suppressed ROS formation in SH-SY5Y cells exposed to $200 \mathrm{ng} / \mathrm{mL}$ TNF $\alpha(1.03 \pm 0.04, n=4)$ to levels indistinguishable from control $(0.99 \pm 0.07, n=4)$ as opposed to TNF $\alpha$ alone $\left(1.91 \pm 0.06, n=4,{ }^{*} P<0.05\right)$. In sharp contrast, a highly polar fraction $\left(\mathrm{PO}_{\mathrm{BB}}\right.$, dark coloration) at $5 \mu \mathrm{g} / \mathrm{mL}$ was ineffective in suppressing TNF $\alpha$-mediated ROS formation $\left(2.53 \pm 0.1, n=4,{ }^{*} P<0.05\right)$. As expected, inhibition of NOX activity with $10 \mu \mathrm{M}$ DPI $(1.07 \pm 0.06, n=4)$ or $1 \mathrm{mM}$ AEBSF $(0.99+0.04, n=4)$ both negated ROS generation in SH-SY5Y cells in response to $200 \mathrm{ng} / \mathrm{mL}$ TNF $\alpha$ as did scavenging ROS with $1 \mathrm{mM} \mathrm{NAC}(0.9 \pm 0.06, n=4)$. Blocking $\mathrm{Mg}^{2+}$-nSMase activity with $13.8 \mu \mathrm{M}$ GW4896 also negated $\mathrm{TNF} \alpha$-stimulated ROS formation $(0.68 \pm 0.26, n=4)$. Activation of NOX in SH-SY5Y cells upon TNF $\alpha$ exposure requires a preceding stimulation of $\mathrm{Mg}^{2+}$-nSMase [30]. The phorbol ester PMA is a well-documented and potent NOX activator bypassing many TNF $\alpha$-dependent upstream signaling events. Exposing SH-SY5Y cells to $400 \mathrm{ng} / \mathrm{mL}$ PMA evoked ROS formation $\left(1.93 \pm 0.30, n=4,{ }^{*} P<0.05\right)$ compared to control $(1.00 \pm 0.08, n=4)$ sensitive to inhibiting NOX with $10 \mu \mathrm{M}$ DPI or $1 \mathrm{mM}$ AEBSF $(0.84 \pm 0.16, n=4$ and $0.52 \pm$ $0.13, n=4$, resp.) as well as ROS scavenging with $1 \mathrm{mM} \mathrm{NAC}$ $(0.96 \pm 0.22, n=4)$ (Figure 1(c)). Preincubation of SH-SY5Y cells with $5 \mu \mathrm{g} / \mathrm{mL} \mathrm{NP} \mathrm{BB}_{\mathrm{BB}}$ also inhibited PMA-stimulated ROS formation $(1.07 \pm 0.16, n=4)$ as opposed to $5 \mu \mathrm{g} / \mathrm{mL} \mathrm{PO}_{\mathrm{BB}}$, which was ineffective $\left(1.85 \pm 0.25, n=4,{ }^{*} P<0.05\right)$ as in the case of TNF $\alpha$. Neither pharmacological inhibitors nor antioxidants significantly suppressed basal ROS levels in SHSY5Y cells (data not shown). Taken together, these findings indicated that extracts obtained from Alaska wild bog blueberries inhibited NOX-dependent ROS formation in neuronal cells exposed to TNF $\alpha$ or PMA. Moreover, this inhibitory potency exhibited an exclusive partition into a nonpolar fraction suggesting the presence of specific natural compounds.

3.2. Nonpolar Blueberry Fractions Exhibit Minimal ROS Scavenging Capacity. Blueberries exhibit an exceptionally high antioxidant capacity compared to other berry fruits, fruits, and vegetables $[33,34]$. Since quantitative measurements of ROS formation in our assay rested on the oxidation of the fluorescence indicator DCF by peroxide, it was imperative to determine the antioxidant capacity of blueberry fractions tested [16]. We employed a choline oxidation assay linking ROS formation produced by choline oxidase to the production of the fluorescent product resorufin $(4.08 \pm 0.05, n=5$, ${ }^{*} P<0.05$ ) (Figure 2). $\mathrm{NP}_{\mathrm{BB}}$ at $5 \mu \mathrm{g} / \mathrm{mL}$ exhibited minimal ROS scavenging capacity $(2.92 \pm 0.27, n=5, * P<0.05)$ and even at a 15 -fold increase in concentration $(75 \mu \mathrm{g} / \mathrm{mL})$ was ineffective $(3.16 \pm 0.25, n=5, * P<0.05)$ at ROS scavenging compared to control (no choline, $1.00 \pm 0.07, n=5$ ) or a presence of $2000 \mathrm{U} / \mathrm{mL}$ catalase $(0.98 \pm 0.04, n=5)$. However, $\mathrm{PO}_{\mathrm{BB}}$ fractions at $75 \mu \mathrm{g} / \mathrm{mL}$ revealed strong ROS scavenging capacity $(1.9 \pm 0.25, * * P<0.05)$ compared to $75 \mu \mathrm{g} / \mathrm{mL}$ $\mathrm{NP}_{\mathrm{BB}}$ fractions, which was not observed for $\mathrm{PO}_{\mathrm{BB}}$ fractions at concentrations of $5 \mu \mathrm{g} / \mathrm{mL}(3.08 \pm 0.15, n=5)$. Neither $\mathrm{NP}_{\mathrm{BB}}$ nor $\mathrm{PO}_{\mathrm{BB}}$ fractions compromised neuronal viability at concentration between $5 \mu \mathrm{g} / \mathrm{mL}$ and $75 \mu \mathrm{g} / \mathrm{mL}$ (Figure 3). In summary, the potency of $\mathrm{NP}_{\mathrm{BB}}$ fractions to inhibit NOXdependent ROS formation was neither attributable to a significant ROS scavenging capacity nor an impairment of neuronal viability but rather suggested a possible interference with the functional assembly of NOX protein subunits.

\subsection{Nonpolar Blueberry Fractions Interfere with Functional} NOX Assembly in Plasma Membranes of SH-SY5Y Cells. Generation of superoxide anions by NOX2 requires the functional assembly of three cytosolic subunits (p67 ${ }^{\text {phox }}, \mathrm{p} 40^{\text {phox }}$, and $\mathrm{p} 47^{\mathrm{phox}}$ ) and two membrane subunits (NOX2, previously gp91 $91^{\text {phox }}$, and $\left.\mathrm{p} 22^{\text {phox }}\right)$ as well as the ancillary small GTPases Rac1 or Rac2 [26]. We investigated whether $\mathrm{NP}_{\mathrm{BB}}$ fractions would specifically interfere with superoxide generation by disrupting proper assembly of NOX2 subunits. Since the oxidation-sensitive, fluorescent indicator DCF is sensitive to several distinct ROS, we employed a cytochrome $\mathrm{C}$ reduction assay in combination with SOD sensitivity to determine superoxide production in SH-SY5Y cells exposed to TNFa (Figure 4(a)). Exposure of SH-SY5Y cells to $200 \mathrm{ng} / \mathrm{mL}$ TNF $\alpha$ stimulated superoxide production (1.48 \pm $0.1, n=2)$ as indicated by its sensitivity to SOD $(200 \mathrm{U} / \mathrm{mL}$ SOD, $1.00 \pm 0.19, n=2$ ) compared to control (no SOD: $0.99+0.09, n=2$; with SOD: $1.00+0.11, n=2$ ). Importantly,

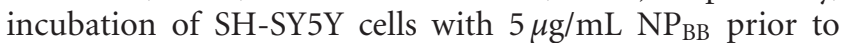
TNF $\alpha$ exposure ( $200 \mathrm{ng} / \mathrm{mL}, 30 \mathrm{~min}$ ) potently blocked superoxide production $(0.84 \pm 0.02, n=2)$ with no further suppression in the presence of SOD $(0.87 \pm 0.14, n=2)$. In contrast, $\mathrm{PO}_{\mathrm{BB}}$ fractions were ineffective in reducing $\mathrm{TNF} \alpha$ mediated superoxide production $(1.19 \pm 0.02, n=2)$ as demonstrated by SOD sensitivity $(0.92 \pm 0.05, n=2)$. As 


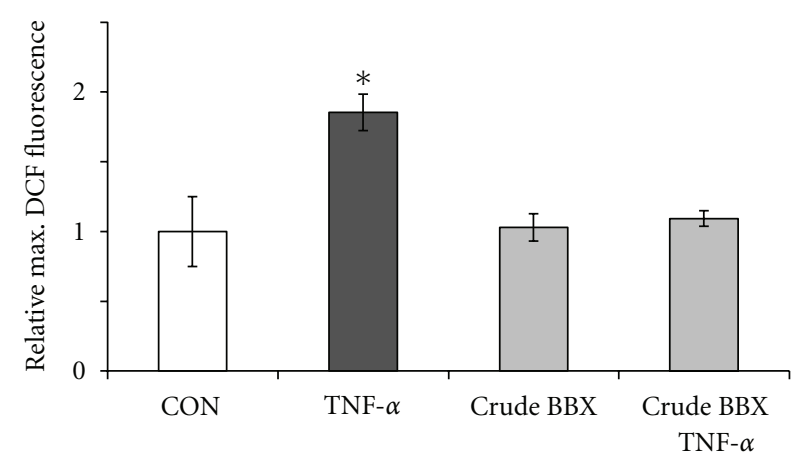

(a)

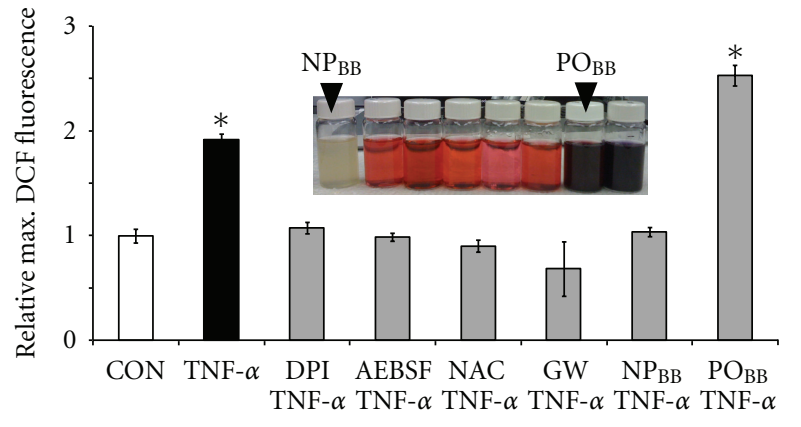

(b)

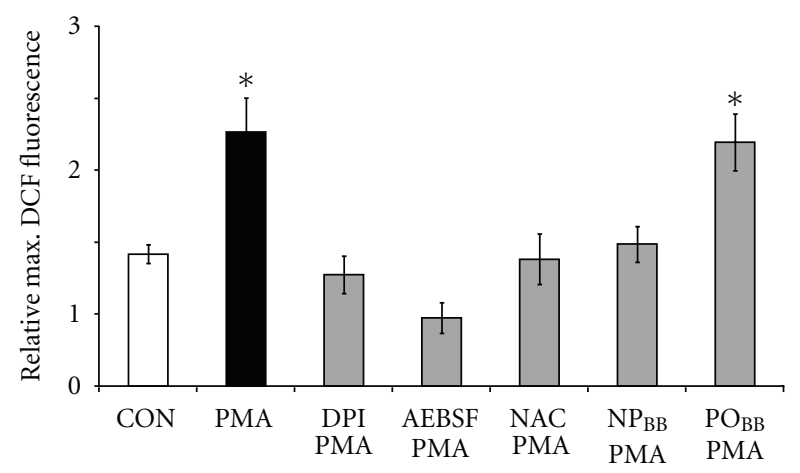

(c)

FIgURE 1: A nonpolar blueberry fraction inhibits oxidative stress in neuroblastoma cells exposed to TNF $\alpha$ and PMA. SH-SY5Y human neuroblastoma cells were loaded with $50 \mu \mathrm{M} \mathrm{H}_{2}$ DCFDA $(1 \mathrm{~h})$ in the presence or absence of pharmacological inhibitors, nonpolar blueberry fractions $\left(\mathrm{NP}_{\mathrm{BB}}\right)$, or polar blueberry fractions $\left(\mathrm{PO}_{\mathrm{BB}}\right)$. Following exposure to $200 \mathrm{ng} / \mathrm{mL}$ TNF $\alpha$ or $400 \mathrm{ng} / \mathrm{mL} \mathrm{PMA}(1 \mathrm{~h})$, maximum DCFfluorescence intensities were measured in whole cell lysates. For the quantification of ROS formation, all measurements were adjusted to total protein and normalized to the average maximum DCF-fluorescence intensity under control conditions. (a) TNF $\alpha$ stimulated a significant increase in relative maximum DCF-fluorescence in SH-SY5Y cells (filled bar) indicative of ROS formation compared to basal ROS levels in controls (open bar). Preincubation with crude blueberry extract $(5 \mu \mathrm{g} / \mathrm{mL})$ negated ROS formation upon exposure to TNF $\alpha$ without affecting basal ROS levels (grey bars). (b) Fractionation of crude blueberry extracts according to increasing polarity produced nonpolar colorless fractions and polar, strongly colored fractions enriched in polyphenolics (insert). Preincubation of SH-SY5Y cells with $5 \mu \mathrm{g} / \mathrm{mL}$ $\mathrm{NP}_{\mathrm{BB}}$ completely suppressed ROS formation upon exposure to TNF $\alpha$ to control levels (open bar) whereas preincubation with $5 \mu \mathrm{g} / \mathrm{mL}$ $\mathrm{PO}_{\mathrm{BB}}$ was ineffective. TNF $\alpha$-stimulated ROS formation was also negated when inhibiting NOX (10 $\mu$ M DPI, 1 mM AEBSF), scavenging ROS (1 mM NAC), or blocking ceramide production (13.8 $\mu \mathrm{M}$ GW4869) (gray bars). (c) PMA exposure of SH-SY5Y cells also induced significant ROS formation (filled bar), which was blocked with $5 \mu \mathrm{g} / \mathrm{mL} \mathrm{NP} \mathrm{BB}_{3}, 10 \mu \mathrm{M}$ DPI, $1 \mathrm{mM}$ AEBSF, or 1 mM NAC compared to control (open bar). PMA-evoked ROS formation was not disrupted by preincubation with $5 \mu \mathrm{g} / \mathrm{mL} \mathrm{PO}_{\mathrm{BB}}$. All data represent the mean of at least four independent experiments \pm standard deviations (SD), and statistical significance was determined at $* P<0.05$ (ANOVA and Tukey's post hoc analysis).

expected, the presence of NOX inhibitors $(10 \mu \mathrm{M}$ DPI or 2 mM AEBSF) or ROS scavengers (2 mM NAC) completely negated TNF $\alpha$-mediated superoxide production (DPI: $0.89 \pm$ $0.06, n=2$; AEBSF: $1.16 \pm 0.05, n=2$; NAC: $0.78 \pm 0.06$, $n=2)$ to control levels with no further suppression by a presence of SOD (DPI: $0.73 \pm 0.26$; AEBSF: $0.98 \pm 0.14$; NAC: $0.81 \pm 0.01$, resp., all $n=2$ ). This study revealed that TNF $\alpha$ elicited preferentially a NOX-dependent superoxide production (values representing mean of 2 independent experiments \pm range). Using an ELISA assay, we quantified relative increases in the plasma membrane association of p6 $7^{\text {phox }}$ in response to TNF $\alpha$ exposure, a commonly accepted indicator for NOX assembly and thus function. As shown in Figure 4(b), incubation of SH-SY5Y cells with $5 \mu \mathrm{g} / \mathrm{mL} \mathrm{NP} \mathrm{BB}_{\mathrm{BB}}$ fraction prior to TNF $\alpha$ exposure ( $200 \mathrm{ng} / \mathrm{mL}, 30 \mathrm{~min}$ ) completely abolished an increase in plasma membrane-associated p67phox $(0.92 \pm 0.06, n=4)$ indistinguishable from control $(1.00 \pm 0.07, n=4)$ in contrast to TNF $\alpha$ exposure alone $(1.60 \pm 0.28, n=4, * P<0.05)$. $\mathrm{PO}_{\mathrm{BB}}$ fractions $(5 \mu \mathrm{g} / \mathrm{mL})$ were ineffective in disrupting a TNF $\alpha$-stimulated increase in plasma membrane-associated p67phox $(1.8 \pm$ $\left.0.06, n=4,{ }^{*} P<0.05\right)$. Utilizing the same experimental paradigm, we directly stimulated NOX assembly using $400 \mathrm{ng} / \mathrm{mL}$ PMA (Figure 4(c)). Indeed, incubation of $\mathrm{SH}-$ SY5Y cells with $5 \mu \mathrm{g} / \mathrm{mL} \mathrm{NP}_{\mathrm{BB}}$ fractions also abolished PMA-mediated increases in plasma membrane-associated p67phox $(1.14 \pm 0.14, n=8)$ to levels similar to control $(1.00 \pm 0.11, n=8)$. In contrast, $\mathrm{PO}_{\mathrm{BB}}$ fractions $(5 \mu \mathrm{g} / \mathrm{mL})$ were ineffective $\left(2.00 \pm 0.21, n=8,{ }^{*} P<0.05\right)$ in disrupting association of p67phox at plasma membrane compared to PMA in the absence of blueberry fractions $\left(2.10 \pm 0.2, n=8,{ }^{*} P<0.05\right)$. Data obtained by 


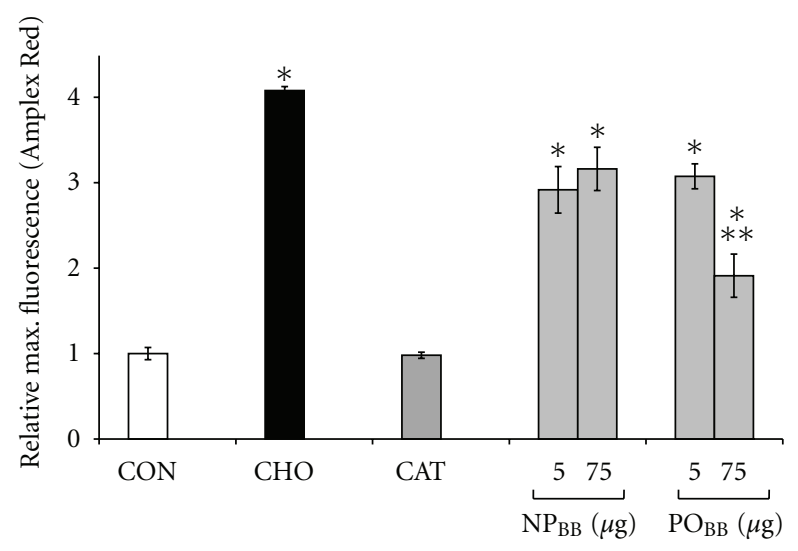

FIGURE 2: Nonpolar blueberry fractions exhibit minimal ROS scavenging capacity. Peroxide generation was quantified via Amplex Red in a direct choline oxidation assay, the conversion of choline to betaine and peroxide by choline oxidase. All fluorescence measurements were normalized to an omission of choline, our control $(\mathrm{CON})$. Addition of choline $(\mathrm{CHO})$ caused significant peroxide formation compared to control $\left({ }^{*} P<0.05\right)$. Neither $5 \mu \mathrm{g} / \mathrm{mL}$ nor $75 \mu \mathrm{g} / \mathrm{ml}$ nonpolar blueberry fraction $\left(\mathrm{NP}_{\mathrm{BB}}\right)$ in the choline oxidation assay displayed any peroxide scavenging capacities compared to $2000 \mathrm{U} / \mathrm{ml}$ catalase (CAT) or controls. Note that the lower concentration of $\mathrm{NP}_{\mathrm{BB}}(5 \mu \mathrm{g} / \mathrm{ml})$ completely abolished ROS formation in SH-SY5Y cells exposed to TNF $\alpha$ or PMA. In contrast, $75 \mu \mathrm{g} / \mathrm{ml}$ of polar blueberry fraction $\left(\mathrm{PO}_{\mathrm{BB}},{ }^{* *} P<0.05\right.$, significantly different from $75 \mu \mathrm{g} / \mathrm{ml} \mathrm{NP}_{\mathrm{BB}}$ ) exhibited considerable peroxide scavenging capacity, which was not observed at a fifteenfold lower concentration $(5 \mu \mathrm{g} / \mathrm{ml})$. Both $\mathrm{NP}_{\mathrm{BB}}$ and $\mathrm{PO}_{\mathrm{BB}}$ at $5 \mu \mathrm{g} / \mathrm{ml}$ caused an overall reduction of Amplex Red fluorescence $\left({ }^{*} P<0.05\right)$, which could imply an interference with Amplex Red fluorescence rather than peroxide scavenging. All data represent the mean of at least four independent experiments \pm standard deviations, and statistical significance was determined at $* P<0.05$ (ANOVA and Tukey's post hoc analysis).

ELISA were corroborated by quantitative western blotting of the relative $\mathrm{p} 67^{\text {phox }}$ content in plasma membrane fractions obtained from SH-SY5Y cells (Figure 5(a)). As anticipated, incubation of SH-SY5Y cells with $5 \mu \mathrm{g} / \mathrm{mL} \mathrm{NP} \mathrm{NB}_{\mathrm{BB}}$ fractions abolished increases in relative levels of plasma membraneassociated p67phox in the presence of $200 \mathrm{ng} / \mathrm{mL} \mathrm{TNF} \alpha$ or $400 \mathrm{ng} / \mathrm{mL}$ PMA $(1.07 \pm 0.23, n=3$, and $1.07 \pm 0.14, n=3$, resp.) as opposed to TNF $\alpha$ or PMA exposure alone $(4.77 \pm$ $0.74, n=3$, and $2.80 \pm 0.50, n=3$, resp., $\left.{ }^{*} P<0.05\right)$. Again, $\mathrm{PO}_{\mathrm{BB}}$ fractions $(5 \mu \mathrm{g} / \mathrm{mL})$ were unable to prevent a TNF $\alpha$ or PMA-mediated increase in relative levels of plasma membrane-associated p67phox $(3.3 \pm 0.65, n=3$ and $3.4 \pm$ $0.12, n=3$, resp., $\left.{ }^{*} P<0.05\right)$.

Since functional activation of NOX2 also requires phosphorylation of the cytosolic subunits $\mathrm{p} 40^{\mathrm{phox}}$ and $\mathrm{p} 47^{\mathrm{phox}}$, we tested whether blueberry fractions would interfere with the phosphorylation of $4^{\text {phox }}$ (Figure 5(b)). Notably, the extent of $\mathrm{p} 40^{\text {phox }}$ phosphorylation in SH-SY5Y cells exposed to PMA was significantly increased regardless of a prior incubation with $5 \mu \mathrm{g} / \mathrm{mL} \mathrm{NP}_{\mathrm{BB}}\left(1.36 \pm 0.26, n=4,{ }^{*} P<0.05\right)$ compared to control $(1.00 \pm 0.1, n=4)$ yet indistinguishable to preincubation with buffer $\left(1.25 \pm 0.18, n=4,{ }^{*} P<0.05\right)$.

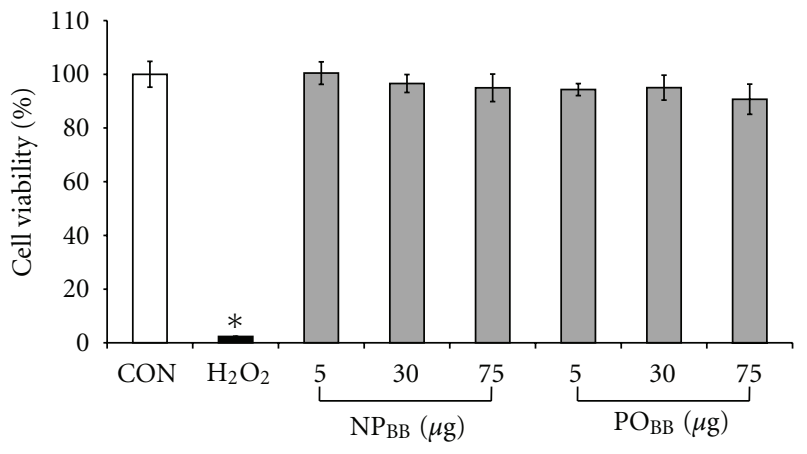

FIGURE 3: Nonpolar and polar blueberry fractions are not cytotoxic. Serum-free cultures of SH-SY5Y cells were supplemented with 5, 30, and $75 \mu \mathrm{g} / \mathrm{mL}$ of nonpolar blueberry fraction $\left(\mathrm{NP}_{\mathrm{BB}}\right)$ or polar blueberry fraction $\left(\mathrm{PO}_{\mathrm{BB}}\right)$ for $48 \mathrm{~h}$. Cell viability was measured using an MTT assay, and all values were normalized to control (CON). Neither $\mathrm{NP}_{\mathrm{BB}}$ nor $\mathrm{PO}_{\mathrm{BB}}$ blueberry fractions compromised cell viability compared to our positive control $\left(\mathrm{H}_{2} \mathrm{O}_{2}, 48 \mathrm{~h}\right)$. Notably, all $\mathrm{NP}_{\mathrm{BB}}$ or $\mathrm{PO}_{\mathrm{BB}}$ concentrations tested potently negated ROS formation in SH-SY5Y cells exposed to TNF $\alpha(200 \mathrm{ng} / \mathrm{mL})$ or PMA $(400 \mathrm{ng} / \mathrm{mL})$. Data represent the mean of eight independent experiments \pm standard deviations, and statistical significance was determined at $* P<0.05$ (ANOVA and Tukey's post hoc analysis).

Taken together, these findings suggested that $\mathrm{NP}_{\mathrm{BB}}$ fractions potently inhibited superoxide generation by NOX resulting from a disruption of the proper assembly of NOX protein subunits at the plasma membrane rather than interfering with upstream signaling pathways responsible for the phosphorylation of cytosolic subunits.

\subsection{Nonpolar Blueberry Fractions Disrupt Functional Assem-} bly of NOX in Lipid Rafts of Neuronal Cells Exposed to TNF $\alpha$ or PMA. Recent evidence obtained in diverse cell types suggests a functional assembly of NOX protein subunits in lipid raft microdomains in response to various extrinsic stimuli $[35,36]$. To address NOX assembly in lipid rafts and the potential interference by blueberry fractions, $\mathrm{SH}$ SY5Y cells were immunostained against GM1 (a lipid raft marker) and p67phox following incubation with blueberry fractions $\left(5 \mu \mathrm{g} / \mathrm{mL} \mathrm{NP}_{\mathrm{BB}}\right.$ or $\left.\mathrm{PO}_{\mathrm{BB}}, 1 \mathrm{~h}\right)$ and exposure to $\mathrm{TNF} \alpha(200 \mathrm{ng} / \mathrm{mL}, 30 \mathrm{~min})$ or PMA (400 ng/mL, $30 \mathrm{~min})$ (Figure 6).

Confocal microscopy revealed basal levels of lipid rafts in SH-SY5Y cells under control conditions, small in size and organized in discontinuous domains, and little colocalization of p67phox (Figure 6(a)). Neither the presence of $\mathrm{NP}_{\mathrm{BB}}$ nor $\mathrm{PO}_{\mathrm{BB}}$ altered the extent and size of lipid raft domains or the degree of p67phox colocalization with lipid raft domains (Figures 6(b) and 6(c)). However, TNF $\alpha$ exposure of SH-SY5Y cells increased both the extent and size of lipid rafts resulting in large, often continuous domains and virtually comprehensive colocalization with p67phox (Figure 6(d)). PMA exposure also caused the formation of large lipid raft macrodomains and extensive $\mathrm{p} 67^{\text {phox }}$ colocalization yet partial appearance of punctate staining suggested the presence of 


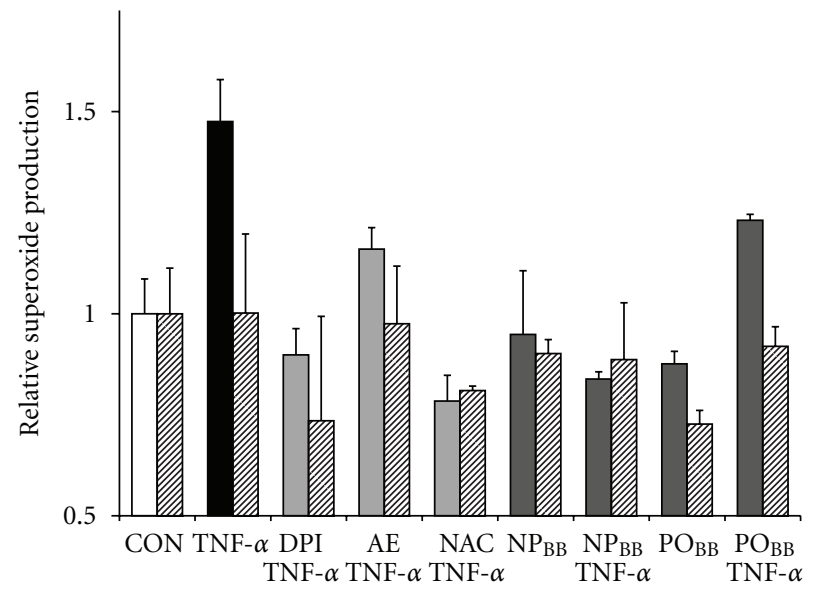

(a)

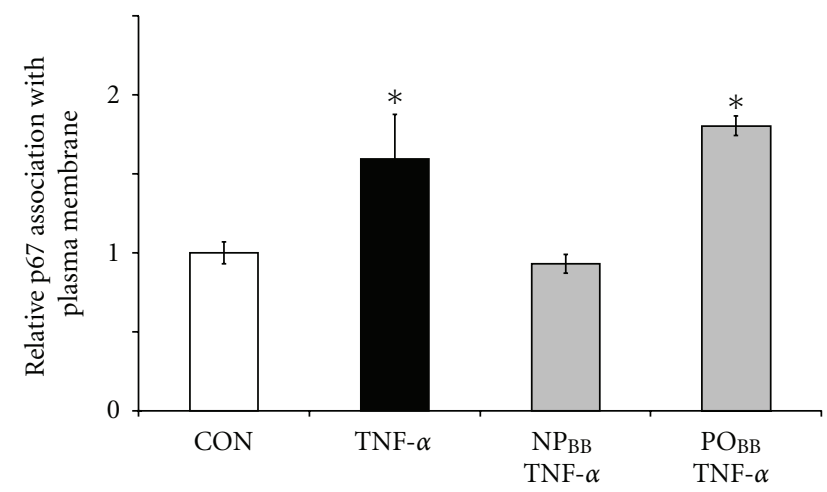

(b)

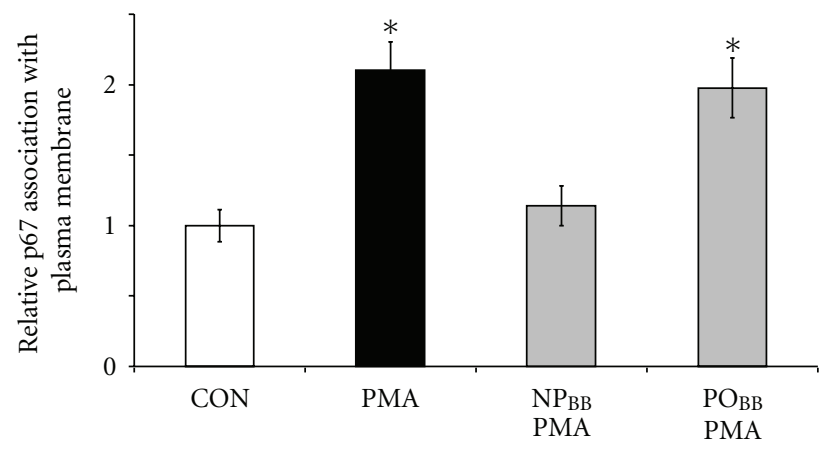

(c)

FIGURE 4: Nonpolar blueberry fractions block superoxide production and abolish p67phox accumulation at plasma membranes in response to $\mathrm{TNF} \alpha$. Serum free cultures of SH-SY5Y were incubated with pharmacological inhibitors or blueberry fractions $\left(\mathrm{NP}_{\mathrm{BB}}\right.$ or POBB $5 \mu \mathrm{g} / \mathrm{mL}$ each, $1 \mathrm{~h})$ prior to TNF $\alpha(200 \mathrm{ng} / \mathrm{mL})$ or PMA $(400 \mathrm{ng} / \mathrm{mL})$ exposure $(30 \mathrm{~min})$ and subjected either to a cytochrome C reduction assay or an ELISA targeting plasma membrane associated p67phox . (a) Cytochrome $\mathrm{C}$ reduction was assayed in whole cell lysates. TNF $\alpha$ exposure of SH-SY5Y cells caused an increase in superoxide production (black bar) as indicated by its sensitivity to a presence of $200 \mathrm{U} / \mathrm{mL}$ SOD (hatched bars in all conditions) compared to control (open bar). Preincubation of SH-SY5Y cells with $10 \mu \mathrm{M}$ DPI, 2 mM AE (AEBSF), or 2 mM NAC all inhibited TNF $\alpha$-mediated superoxide production (light grey bars). Also, pretreatment of SH-SY5Y cells with nonpolar blueberry fractions $\left(\mathrm{NP}_{\mathrm{BB}}\right)$ negated superoxide production upon exposure to TNF $\alpha$ (dark grey bars) as suggested by SOD sensitivity. In contrast, pretreatment of SH-SY5Y cells with polar blueberry fractions $\left(\mathrm{PO}_{\mathrm{BB}}\right)$ was ineffective in abolished TNF $\alpha$-mediated superoxide production. All data was normalized to control and represent the mean of two independent experiments \pm range. (b and c) Plasma membrane-associated p67phox was quantified ( $20 \mu \mathrm{g} / \mathrm{mL}$ total membrane protein) using an ELISA (see Section 2) after sucrose gradient centrifugation of cell lysates to obtain a plasma membrane fraction. (b) TNF $\alpha$ exposure of SH-SY5Y cells significantly increases plasma membrane-association of p67phox (filled bar) compared to control (open bar). Preincubation of SH-SY5Y cells with $\mathrm{NP}_{\mathrm{BB}}$ completely blocked an association of p67phox with plasma membranes upon addition of TNF $\alpha$ whereas preincubation with $\mathrm{PO}_{\mathrm{BB}}$ was ineffective (grey bars). (c) PMA also stimulated an increase in p67phox association with plasma membranes (filled bar) in SH-SY5Y cells compared to control (open bar). As in the case of TNF $\alpha$, preincubation of $\mathrm{SH}-\mathrm{SY} 5 \mathrm{Y}$ cells with $\mathrm{NP}_{\mathrm{BB}}$ successfully negated an association of p67 ${ }^{\text {phox }}$ with plasma membranes (grey bars) compared to control (open bar). Preincubation of SH-SY5Y cells with $\mathrm{PO}_{\mathrm{BB}}$ did not negate PMA-mediated p67phox plasma membrane association. All values were normalized to control, data represent the mean of at least four independent experiments \pm standard deviations, and statistical significance was determined at ${ }^{*} P<0.05$ (ANOVA and Tukey's post hoc analysis).

spatially discrete domains (Figure 6(g)). Importantly, pretreatment of SH-SY5Y cells with $\mathrm{NP}_{\mathrm{BB}}$ almost completely abolished the formation of a lipid raft continuum with p67phox colocalization upon exposure to TNF $\alpha$ or PMA (Figures 6(e) and 6(h)). Punctate appearance of lipid raft and greatly diminished $\mathrm{p} 67^{\mathrm{phox}}$ colocalization resembled control conditions. In contrast, incubation of SH-SY5Y cells with
$\mathrm{PO}_{\mathrm{BB}}$ revealed no interference with the formation of lipid raft macrodomains and $\mathrm{p} 67^{\mathrm{phox}}$ colocalization in response to TNF $\alpha$ or PMA (Figures 6(f) and 6(i)).

In summary, these findings demonstrate that nonpolar blueberry fractions potently interfere with the formation and congealing of large lipid raft macrodomains in response to TNF $\alpha$ or PMA. Moreover, this apparent modulation of lipid 


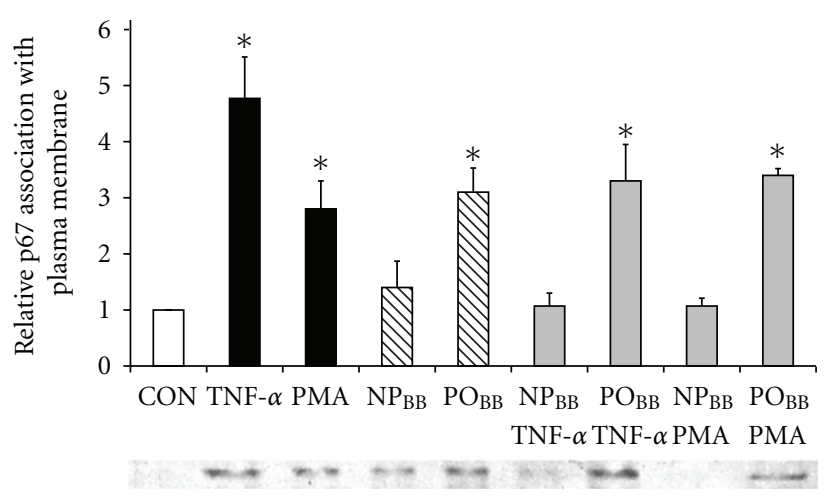

(a)

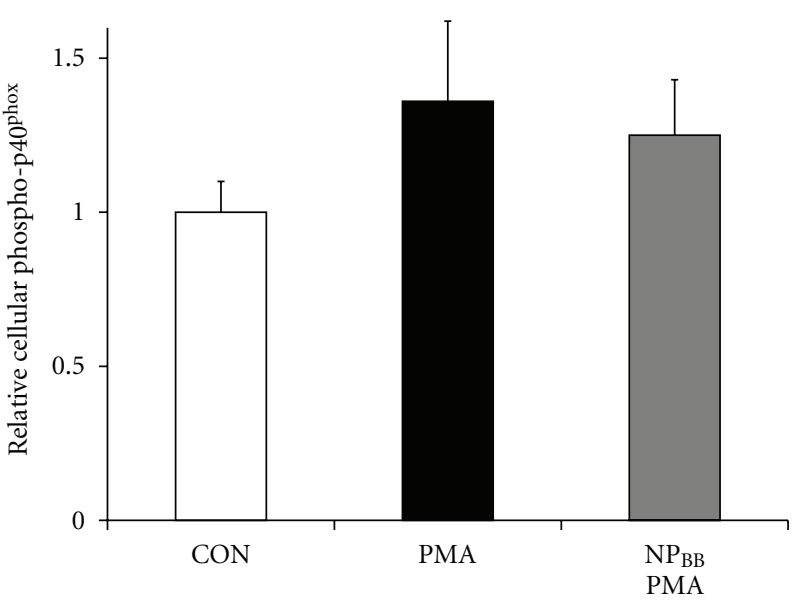

(b)

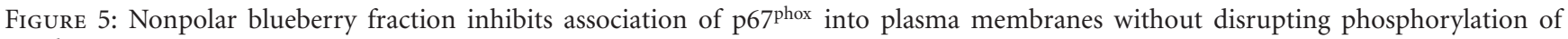
$\mathrm{p} 40^{\text {phox }}$. Serum free cultures of SH-SY5Y cells were incubated with nonpolar $\left(\mathrm{NP}_{\mathrm{BB}}\right)$ and polar $\left(\mathrm{PO}_{\mathrm{BB}}\right)$ blueberry fractions $(5 \mu \mathrm{g} / \mathrm{mL}$ each, $1 \mathrm{~h})$ prior to insult with $200 \mathrm{ng} / \mathrm{mL}$ TNF $\alpha$ or $400 \mathrm{ng} / \mathrm{mL}$ PMA (30 min). (a) After cell lysis and subcellular fractionation, equal amounts of total plasma membrane protein were subjected to SDS gel electrophoresis followed by western blotting, immunoreactivity against p67phox (colorimetric detection) was quantified by densitometry (ImageJ64), and all values were normalized to control. TNF $\alpha$ and PMA (filled bars, resp.) induced significant association of $6^{67^{\text {phox }}}$ in plasma membrane fractions compared to control (open bar). Preincubation of SH-SY5Y cells with $\mathrm{NP}_{\mathrm{BB}}$ prevented $\mathrm{p} 67^{\text {phox }}$ plasma membrane association regardless of stimulus (TNF $\alpha$ or PMA) whereas preincubation with $\mathrm{PO} \mathrm{BB}_{\mathrm{B}}$ was ineffective. Note that incubation of SH-SY5Y cells with $\mathrm{PO}_{\mathrm{BB}}$ alone but not $\mathrm{NP}_{\mathrm{BB}}$ resulted in a significant increase in p67phox plasma membrane association. (b) Immunoreactivity against phosphorylated p40 ${ }^{\text {phox }}$ was determined in whole cell lysates (ELISA). All data was adjusted total cellular protein (BCA assay) and normalized to controls. Exposure to $400 \mathrm{ng} / \mathrm{mL}$ PMA significantly stimulated phosphorylation of $440^{\text {phox }}$ (solid bar), necessary for NOX activity, compared to control (CON, open bar). Importantly, pretreatment of SH-SY5Y cells with $5 \mu \mathrm{g} / \mathrm{mL} \mathrm{NP}_{\mathrm{BB}}$ had no effect on the extent of $\mathrm{p} 0^{\text {phox }}$ phosphorylation (grey bar). All data represent the mean of at least four independent experiments \pm standard error of the mean (SEM), and statistical significance was determined at $* P<0.05$ (ANOVA and Tukey's post hoc analysis).

raft domains also interfered with the plasma membrane association of p67phox indicative for disrupting NOX assembly.

\section{Discussion}

Here, we report for the first time that wild Alaska bog blueberries (Vaccinium uliginosum) harbor the capacity to effectively obstruct coalescing of lipid rafts into larger platforms hence impeding the assembly of NOX2, specifically the association of the cytosolic p67phox subunit with NOX2 and gp2 $21^{\text {phox }}$ in plasma membranes, and thus disrupt ROS generation. This capacity discretely partitioned into a nonpolar fraction $\left(\mathrm{NP}_{\mathrm{BB}}\right)$ and was not only equally effective as DPI or AEBSF in inhibiting NOX2 but also not cytotoxic. We demonstrated previously that superoxide generated by NOX2 is the principal source of ROS in SH-SY5Y neuroblastoma cells exposed to $\mathrm{TNF} \alpha$ [21]. ROS quantification using both DCF and dihydroethidium, a superoxide-specific fluorescence indicator, revealed the exclusive oxidation of dihydroethidium. Since dihydroethidium exhibits considerable cytotoxicity and potential concentration-dependent artifacts, we quantified ROS generation in this study relying on DCF. To corroborate superoxide formation in SH-SY5Y cells exposed to $\mathrm{TNF} \alpha$, we employed a cytochrome $\mathrm{C}$ reduction assay using whole lysates either in the presence or absence of exogenous SOD (Figure 4(a)). Importantly, nonpolar blueberry fractions $\left(\mathrm{NP}_{\mathrm{BB}}\right)$ potently abolished NOX-dependent superoxide production in sharp contrast to polar blueberry fractions $\left(\mathrm{PO}_{\mathrm{BB}}\right)$. Several findings strongly suggested a nonantioxidant action of this NOX inhibitor in suppressing NOX-dependent ROS generation. First, the NOX inhibitor discretely partitioned into the most nonpolar milieu suggesting a nature of compounds other than polyphenolics, which collected in more polar fractions. Second, the NOX inhibitor impeded the association of the cytosolic subunit p6 $7^{\text {phox }}$ at the plasma membrane, a critical step in the assembly of a functional NOX complex. And third, the NOX inhibitor exhibited minimal if any ROS scavenging capacity. Although NOX inhibitory concentrations $(5 \mu \mathrm{g} / \mathrm{mL})$ in $\mathrm{NP}_{\mathrm{BB}}$ reduced peroxide production (Amplex Red detection) in our choline oxidation assay, no additional antioxidant capacity was apparent at fifteenfold higher concentrations $(75 \mu \mathrm{g} / \mathrm{mL})$. In sharp contrast, polar fractions $\left(\mathrm{PO}_{\mathrm{BB}}\right)$ composed largely of polyphenolic compounds did exhibit antioxidant capacity at fifteenfold higher concentrations [33, 34]. Thus it might be plausible that blueberry fractions partially interfered with the Amplex Red fluorescence per se and not ROS production. To account for decreased NOX activity due to cytotoxic effects of both blueberry fractions, we measured the cell viability of SH-SY5Y cells treated with nonpolar or polar fractions. Neither fraction compromised cell viability ranging from experimental concentration $(5 \mu \mathrm{g} / \mathrm{mL})$ up to fifteenfold higher concentrations $(75 \mu \mathrm{g} / \mathrm{mL})$. Moreover, the inhibitory potency of nonpolar fractions is insensitive to heating ( 5 min, boiling waterbath) implying a small molecular weight, nonprotein compound (data not shown). Present 


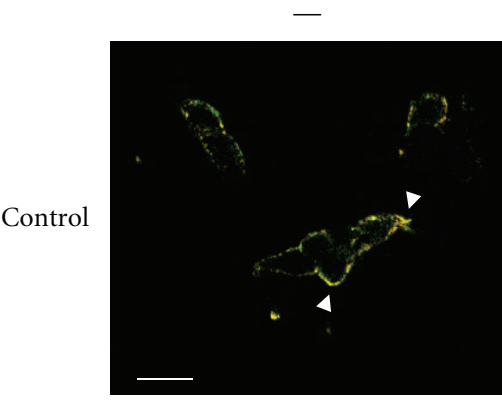

(a)

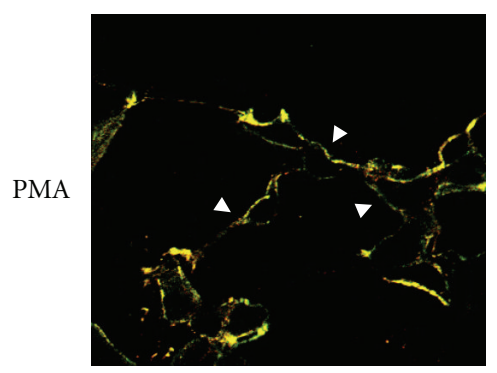

(d)

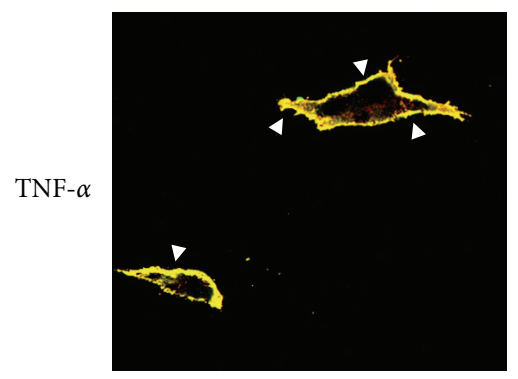

(g)

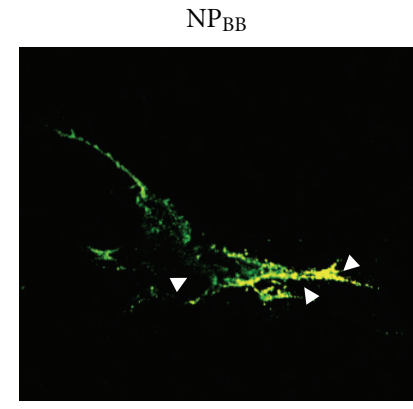

(b)

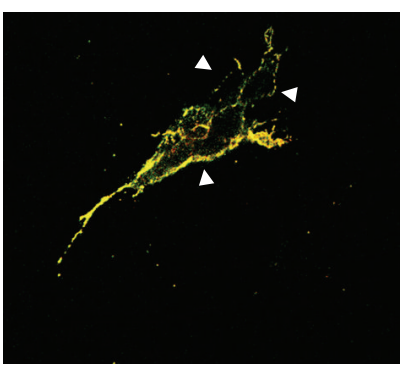

(e)

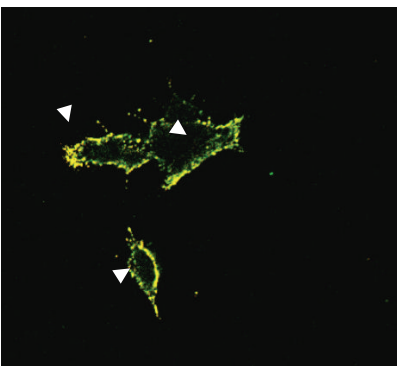

(h)

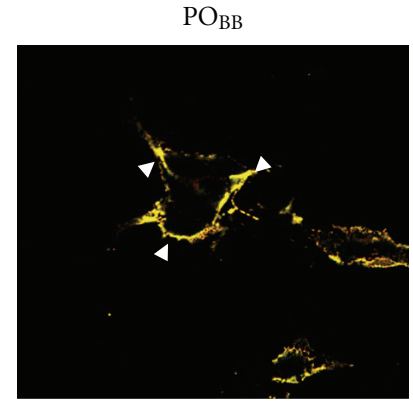

(c)

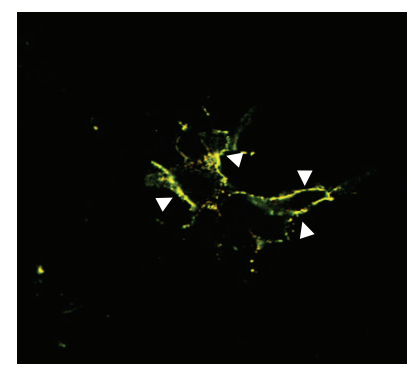

(f)

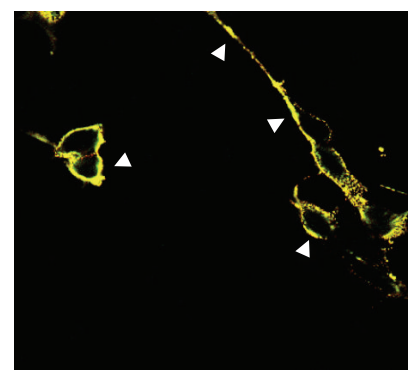

(i)

Figure 6: Nonpolar blueberry fraction inhibits the association of p67phox to the plasma membrane by modulating lipid raft platforms. SHSY5Y cells were grown on polylysine-coated glass cover slips and following serum starvation (overnight), incubated with nonpolar ( $\mathrm{NP}_{\mathrm{BB}}$ ) or polar $\left(\mathrm{PO}_{\mathrm{BB}}\right)$ blueberry fractions $(5 \mu \mathrm{g} / \mathrm{mL}$ each, $1 \mathrm{~h})$ prior to insult $(200 \mathrm{ng} / \mathrm{mL} \mathrm{TNF} \alpha$ or $400 \mathrm{ng} / \mathrm{mL}$ PMA, resp., $30 \mathrm{~min})$. Live cultures were stained for lipid rafts (Alexa Fluor 555 lipid raft labeling kit), then fixed with 4\% paraformaldehyde, immunostained against p67phox, and mounted with PVA-DABCO. Images were acquired (Zeiss LSM510 confocal microscope) under rhodamine illumination (lipid rafts) and fluorescein illumination (p67phox). Image overlay demonstrated colocalization of p67 phox and lipid rafts (yellow, arrow heads). SHSY5Y cells under control conditions displayed very little colocalization of p67phox with lipid rafts and the punctate staining is indicative of small dimension lipid raft domains (a). SH-SY5Y cells treated with $\mathrm{NP}_{\mathrm{BB}}$ revealed a lipid raft-p67 ${ }^{\text {phox }}$ colocalization indistinguishable from controls (b). In contrast, SH-SY5Y cells treated with $\mathrm{PO}_{\mathrm{BB}}$ exhibited increased colocalization of p67phox and lipid rafts (c). As expected, $\mathrm{TNF} \alpha$ exposure induced the formation of large, virtually continuous lipid raft macrodomains and almost complete colocalization with p67 $7^{\text {phox }}(\mathrm{d})$. Preincubation of SH-SY5Y cells with $\mathrm{NP}_{\mathrm{BB}}$ potently interfered with the formation of lipid raft macrodomains with virtually no p67phox colocalization upon exposure to $\mathrm{TNF} \alpha$ (e) and the punctate, discontinuous staining patterns strongly resembled control conditions. Treatment of SH-SY5Ywith $\mathrm{PO}_{\mathrm{BB}}$ prior to $\mathrm{TNF} \alpha$ insult had no effect on lipid raft-p67phox colocalization or lipid raft macrodomain formation (f). Similarly, SH-SY5Y cells responded to PMA exposure with the formation of lipid raft macrodomains and substantial p67phox colocalization although to a lesser extent compared to TNF $\alpha$ (g). Treatment of SH-SY5Y cells with NP ${ }_{\mathrm{BB}}$ prior to PMA insult diminished the formation of lipid raft macrodomains and p67phox colocalization albeit less potently compared to a TNF $\alpha$ insult (h). $\mathrm{PO}_{\mathrm{BB}}$ preincubation of SH-SY5Y was ineffective (i) (scale bar $=20 \mu \mathrm{m})$.

pharmacology (DPI, AEBSF) against NOX activities suffers from considerable cytotoxicity and lack of specificity [29]. Only a few natural products thus far are reported to block NOX-dependent ROS generation likely via non-antioxidant mechanisms. The plant phenol apocynin interferes with NOX assembly although it failed to inhibit several NOX isoforms [37-39]. Prodigiosin, a microbial pigment, and some derivatives suppressed NOX activity most likely by disrupting Rac function, and inhibition of NOX by the alkaloid sinomenine is unclear at best [40-42]. In our case, complete isolation and characterization of the NOX inhibiting natural compound present in extracts of wild Alaska bog blueberries, specifically $\mathrm{NP}_{\mathrm{BB}}$ fractions, was beyond the realm of this study. 
Next we investigated whether the blueberry-derived NOX inhibiting bioactivity could alter the plasma membrane properties such as lipid rafts. In many cell types, extrinsic stimuli including TNF $\alpha$ induce NOX assembly in lipid raft platforms, microdomains of distinct lipid, and protein composition serving as redox signaling platforms [25, 35, 4345]. Both PMA and TNF $\alpha$ mediate NOX activation at least partially through increases in the bioactive lipids arachidonic acid and ceramide. Lastly, the NOX-inhibiting bioactivity was nonpolar in nature and exhibited minimal antioxidant capacity. Both ELISA and western blotting revealed increase plasma membrane association of $\mathrm{p} 67^{\mathrm{phox}}$ in response to TNF $\alpha$ or PMA and complete interference by preincubation of SH-SY5Y cells with $\mathrm{NP}_{\mathrm{BB}}$. In sharp contrast, phosphorylation of the cytosolic subunit $\mathrm{p} 40^{\mathrm{phox}}$, also essential for NOX activation, was not impaired in SH-SY5Y cells treated with $\mathrm{NP}_{\mathrm{BB}}$ prior to PMA exposure. Together these findings strongly argue for $\mathrm{NP}_{\mathrm{BB}}$ interfering at the level of plasma membrane organization as opposed to disrupting intracellular kinase signaling. Interestingly, treatment of SH-SY5Y cells with $5 \mu \mathrm{g} / \mathrm{mL} \mathrm{PO}_{\mathrm{BB}}$ alone revealed a significant increase in $67^{\text {phox }}$ plasma membrane association in sharp contrast to $\mathrm{NP}_{\mathrm{BB}}$ treatment indicative of a modest activation of NOX by $\mathrm{PO}_{\mathrm{BB}}$ fractions. Yet consistent failure to measure ROS output in SH-SY5Y cells treated with $\mathrm{PO}_{\mathrm{BB}}$ could simply indicate that $\mathrm{p} 67^{\mathrm{phox}}$ plasma membrane association without a representative ROS measurement is insufficient to claim NOX activation. Alternatively, this finding could reveal a hormetic NOX stimulation by blueberries, a modest output of ROS utilized rapidly for redox regulation and thus remaining undetectable [46-48]. Modest oxidative stress is documented to enhance antioxidant defense of cells possibly mediated by Nrf2 or NF $\kappa$ B [49]. Since both ELISA and western blotting lacked sufficient signal strength to analysis p67phox content in relation to lipid rafts, we employed immunocytochemistry in combination with confocal microscopy. Binding of cholera toxin to the ganglioside GM1, a distinct lipid raft marker, was used to reveal the presence of lipid rafts [50]. As expected, SH-SY5Y cells displayed a basal level of lipid raft density in plasma membranes under control conditions. The predominant fine punctate appearance of staining was interpreted as spatially distinct, small dimension lipid rafts. The minimal colocalization of $\mathrm{p} 67^{\text {phox }}$ with small lipid rafts would support basal NOX activity potentially contributing to physiological redox signaling. However, upon exposure to TNF $\alpha, \mathrm{SH}-\mathrm{SY} 5 \mathrm{Y}$ cells displayed extensive cholera toxin staining suggesting the coalescing of small dimension lipid rafts into large platforms as well as a substantial colocalization of $\mathrm{p} 67^{\text {phox }}$ within large lipid raft platforms. Most significantly, treatment of $\mathrm{SH}$ SY5Y cells with nonpolar blueberry fractions, containing NOX inhibitory potency, prior to TNF $\alpha$ exposure only obstructed the coalescing of small lipid rafts into larger platforms and colocalization of $\mathrm{p} 67^{\mathrm{phox}}$ within, with no apparent effect on the presence and density of small lipid rafts whereas polar fractions were ineffective. Methyl- $\beta$-cyclodextrin (a cholesterol-sequestering agent) also blocked TNF $\alpha$-mediated NOX activation [51]. Yet in stark contrast to our nonpolar blueberry fraction, methyl- $\beta$-cyclodextrin completely depleted lipid rafts of all dimensions even under control con- ditions likely explaining its high cytotoxic (data not shown). The bioactive lipid ceramide plays a key role in establishing a membrane microenvironment conducive to the formation of lipid raft structures. Sphingomyelin, an abundant lipid in neuronal plasma membranes, is hydrolyzed by sphingomyelinases constituting a principal source of ceramide generation aside from de novo synthesis. We have demonstrated that TNF $\alpha$ exposure of SH-SY5Y cells stimulates a $\mathrm{Mg}^{2+}$-dependent neutral sphingomyelinase activity, which precedes ROS generation by NOX2 [30]. It is noteworthy that pretreatment of SH-SY5Y cells with wild Alaska bog blueberry extracts or $\mathrm{NP}_{\mathrm{BB}}(5 \mu \mathrm{g} / \mathrm{mL}$ each $)$ inhibited neutral sphingomyelinase activity in neurons exposed to TNF $\alpha$ with minimal antioxidant capacity [16]. Alteration of membrane properties by natural products has been demonstrated in vitro and in vivo and dietary intake of EPA, DHA, and other lipids reportedly alter lipid rafts. Our own studies demonstrated that increasing glucosylceramide content in plasma membrane of SH-SY5Y cells negated NOX activation in response to TNF $\alpha$ likely by altering membrane properties [52]. However, the extraction conditions employed in our experiments eliminate the presence of these compounds in nonpolar blueberry fractions $[53,54]$.

A plethora of studies demonstrates significant health benefits of nutrient rich fruits as well as vegetables and mounting evidence attributes the potential of epigenetic modulation for intervention of aging processes or complex pathologies such as inflammation, cancer, obesity, and chronic CNS diseases $[2,4,14,55]$. Dietary intake of blueberries increased resilience of neurons to acute CNS insult and improved memory and cognition in aging animals and humans $[8-10,56]$. Although much research focuses on polyphenolic compounds and their antioxidant properties, particularly flavonoids, more recent evidence has supported direct actions on cellular targets including transcription factors, kinases, and lipases [3]. We demonstrated the presence of a nonpolar bioactivity in extracts of wild Alaska blueberries, which negated a functional NOX assembly and hence decreased ROS production in SH-SY5Y human neuroblastoma cells exposed to TNF $\alpha$. This inhibition was likely not antioxidant in nature yet appeared to result from an obstruction of plasma membrane reorganization into large lipid raft platforms. Members of the NOX family have gained interest as sources of oxidative stress in aging processes, mild cognitive disorders, and a number of chronic pathologies. These studies indicated for the first time the presence of potent NOX inhibitory bioactivity in wild Alaska bog blueberries. The implied action of lipid raft modulation could illuminate novel therapeutic approaches to potentially blunt inflammatory and oxidative stresses associated with an aging or diseased CNS.

\section{Funding}

This paper was supported by National Institutes of Health Grant (1U54NS41069) and United States Department of Agriculture Grant 2005-34495-16519. 


\section{Acknowledgments}

The authers would like to thank Dr. L. Duffy and Dr. B. Hale for critical input in the preparation of this paper and constructive discussion of this research. They immensely appreciate the strong support of Dr. J. Joseph and his mentorship in regards to thier research endeavors at the crossroads of nutrition and neuroscience.

\section{References}

[1] S. M. Lucas, N. J. Rothwell, and R. M. Gibson, "The role of inflammation in CNS injury and disease," British Journal of Pharmacology, vol. 147, no. 1, pp. S232-S240, 2006.

[2] A. Y. Sun, Q. Wang, A. Simonyi, and G. Y. Sun, "Botanical phenolics and brain health," NeuroMolecular Medicine, vol. 10, no. 4, pp. 259-274, 2008.

[3] J. P. E. Spencer, "The impact of fruit flavonoids on memory and cognition," British Journal of Nutrition, vol. 104, no. 3, pp. S40-S47, 2010.

[4] K. Szarc vel Szic, M. N. Ndlovu, G. Haegeman, and W. Vanden Berghe, "Nature or nurture: let food be your epigenetic medicine in chronic inflammatory disorders," Biochemical Pharmacology, vol. 80, no. 12, pp. 1816-1832, 2010.

[5] R. L. Galli, B. Shukitt-Hale, K. A. Youdim, and J. A. Joseph, "Fruit polyphenolics and brain aging: nutritional interventions targeting age-related neuronal and behavioral deficits," Annals of the New York Academy of Sciences, vol. 959, pp. 128132, 2002.

[6] J. A. Joseph, N. A. Denisova, D. Bielinski, D. R. Fisher, and B. Shukitt-Hale, "Oxidative stress protection and vulnerability in aging: putative nutritional implications for intervention," Mechanisms of Ageing and Development, vol. 116, no. 2-3, pp. 141-153, 2000.

[7] F. C. Lau, D. F. Bielinski, and J. A. Joseph, "Inhibitory effects of blueberry extract on the production of inflammatory mediators in lipopolysaccharide-activated BV2 microglia," Journal of Neuroscience Research, vol. 85, no. 5, pp. 1010-1017, 2007.

[8] B. Shukitt-Hale, F. C. Lau, and J. A. Joseph, "Berry fruit supplementation and the aging brain," Journal of Agricultural and Food Chemistry, vol. 56, no. 3, pp. 636-641, 2008.

[9] M. I. Sweeney, W. Kalt, S. L. MacKinnon, J. Ashby, and K. T. Gottschall-Pass, "Feeding rats diets enriched in lowbuch blueberries for six weeks decreases ischemia-induced brain damage," Nutritional Neuroscience, vol. 5, no. 6, pp. 427-431, 2002.

[10] R. Krikorian, M. D. Shidler, T. A. Nash et al., "Blueberry supplementation improves memory in older adults," Journal of Agricultural and Food Chemistry, vol. 58, no. 7, pp. 3996-4000, 2010.

[11] G. Borges, A. Degeneve, W. Mullen, and A. Crozier, "Identification of flavonoid and phenolic antioxidants in black currants, blueberries, raspberries, red currants, and cranberries," Journal of Agricultural and Food Chemistry, vol. 58, no. 7, pp. 3901-3909, 2010.

[12] N. P. Seeram, "Berry fruits: compositional elements, biochemical activities, and the impact of their intake on human health, performance, and disease," Journal of Agricultural and Food Chemistry, vol. 56, no. 3, pp. 627-629, 2008.

[13] C. M. Williams, M. A. El Mohsen, D. Vauzour et al., "Blueberry-induced changes in spatial working memory correlate with changes in hippocampal CREB phosphorylation and brain-derived neurotrophic factor (BDNF) levels," Free Radical Biology and Medicine, vol. 45, no. 3, pp. 295-305, 2008.

[14] K. Vafeiadou, D. Vauzour, and J. P. E. Spencer, "Neuroinflammation and its modulation by flavonoids," Endocrine, Metabolic and Immune Disorders - Drug Targets, vol. 7, no. 3, pp. 211-224, 2007.

[15] N. H. Nam, "Naturally occurring NF- $\kappa$ B inhibitors," MiniReviews in Medicinal Chemistry, vol. 6, no. 8, pp. 945-951, 2006.

[16] S. J. Gustafson, B. M. Barth, C. M. McGill, T. P. Clausen, and T. B. Kuhn, "Wild Alaskan blueberry extracts inhibit a magnesium-dependent neutral sphingomyelinase activity in neurons exposed to TNF $\alpha$," Current Topics in Nutraceutical Research, vol. 5, no. 4, pp. 183-188, 2007.

[17] S. Amor, F. Puentes, D. Baker, and P. Van Der Valk, "Inflammation in neurodegenerative diseases," Immunology, vol. 129, no. 2, pp. 154-169, 2010.

[18] S. Chakraborty, D. K. Kaushik, M. Gupta, and A. Basu, "Inflammasome signaling at the heart of central nervous system pathology," Journal of Neuroscience Research, vol. 88, no. 8, pp. 1615-1631, 2010.

[19] S. P. Tammariello, M. T. Quinn, and S. Estus, "NADPH oxidase contributes directly to oxidative stress and apoptosis in nerve growth factor-deprived sympathetic neurons," The Journal of Neuroscience, vol. 20, no. 1, article RC53, 2000.

[20] K. M. Noh and J. Y. Koh, "Induction and activation by zinc of NADPH oxidase in cultured cortical neurons and astrocytes," The Journal of Neuroscience, vol. 20, no. 23, article RC111, 2000.

[21] B. M. Barth, S. Stewart-Smeets, and T. B. Kuhn, "Proinflammatory cytokines provoke oxidative damage to actin in neuronal cells mediated by Rac1 and NADPH oxidase," Molecular and Cellular Neuroscience, vol. 41, no. 2, pp. 274-285, 2009.

[22] P. L. Hordijk, "Regulation of NADPH oxidases: the role of Rac proteins," Circulation Research, vol. 98, no. 4, pp. 453-462, 2006.

[23] Y. Groemping and K. Rittinger, "Activation and assembly of the NADPH oxidase: a structural perspective," Biochemical Journal, vol. 386, no. 3, pp. 401-416, 2005.

[24] H. Sumimoto, K. Miyano, and R. Takeya, "Molecular composition and regulation of the Nox family NAD(P)H oxidases," Biochemical and Biophysical Research Communications, vol. 338, no. 1, pp. 677-686, 2005.

[25] P. L. Li and E. Gulbins, "Lipid rafts and redox signaling," Antioxidants and Redox Signaling, vol. 9, no. 9, pp. 1411-1415, 2007.

[26] K. Bedard and K. H. Krause, "The NOX family of ROS-generating NADPH oxidases: physiology and pathophysiology," Physiological Reviews, vol. 87, no. 1, pp. 245-313, 2007.

[27] K. H. Krause, "Aging: a revisited theory based on free radicals generated by NOX family NADPH oxidases," Experimental Gerontology, vol. 42, no. 4, pp. 256-262, 2007.

[28] J. D. Lambeth, "Nox enzymes, ROS, and chronic disease: an example of antagonistic pleiotropy," Free Radical Biology and Medicine, vol. 43, no. 3, pp. 332-347, 2007.

[29] J. D. Lambeth, K. H. Krause, and R. A. Clark, "NOX enzymes as novel targets for drug development," Seminars in Immunopathology, vol. 30, no. 3, pp. 339-363, 2008.

[30] B. M. Barth, S. J. Gustafson, and T. B. Kuhn, "Neutral sphingomyelinase activation precedes NADPH oxidase-dependent damage in neurons exposed to the proinflammatory cytokine tumor necrosis factor- $\alpha$," Journal of Neuroscience Research, vol. 90, no. 1, pp. 229-242, 2012. 
[31] A. Abo, A. Boyhan, I. West, A. J. Thrasher, and A. W. Segal, "Reconstitution of neutrophil NADPH oxidase activity in the cell-free system by four components: p67-phox, p47-phox, p21rac1, and cytochrome b-245," Journal of Biological Chemistry, vol. 267, no. 24, pp. 16767-16770, 1992.

[32] J. M. Li and A. M. Shah, "Intracellular localization and preassembly of the NADPH oxidase complex in cultured endothelial cells," Journal of Biological Chemistry, vol. 277, no. 22, pp. 19952-19960, 2002.

[33] S. Y. Wang, C. T. Chen, W. Sciarappa, C. Y. Wang, and M. J. Camp, "Fruit quality, antioxidant capacity, and flavonoid content of organically and conventionally grown blueberries," Journal of Agricultural and Food Chemistry, vol. 56, no. 14, pp. 5788-5794, 2008.

[34] K. L. Wolfe, X. Kang, X. He, M. Dong, Q. Zhang, and R. H. Liu, "Cellular antioxidant activity of common fruits," Journal of Agricultural and Food Chemistry, vol. 56, no. 18, pp. 84188426, 2008.

[35] D. Shao, A. W. Segal, and L. V. Dekker, "Lipid rafts determine efficiency of NADPH oxidase activation in neutrophils," FEBS Letters, vol. 550, no. 1-3, pp. 101-106, 2003.

[36] F. Yi, S. Jin, and P. L. Li, "Lipid raft-redox signaling platforms in plasma membrane," Methods in Molecular Biology, vol. 580, pp. 93-107, 2009.

[37] J. M. Simons, B. A. 't Hart, T. R. A. M. Ip Vai Ching, H. Van Dijk, and R. P. Labadie, "Metabolic activation of natural phenols into selective oxidative burst agonists by activated human neurophils," Free Radical Biology and Medicine, vol. 8, no. 3, pp. 251-258, 1990.

[38] J. Stolk, T. J. Hiltermann, J. H. Dijkman, and A. J. Verhoeven, "Characteristics of the inhibition of NADPH oxidase activation in neutrophils by apocynin, a methoxy-substituted catechol," American journal of respiratory cell and molecular biology, vol. 11, no. 1, pp. 95-102, 1994.

[39] S. Heumüller, S. Wind, E. Barbosa-Sicard et al., "Apocynin is not an inhibitor of vascular NADPH oxidases but an antioxidant," Hypertension, vol. 51, no. 2, pp. 211-217, 2008.

[40] A. A. Finegold, K. P. Shatwell, A. W. Segal, R. D. Klausner, and A. Danois, "Intramembrane bis-heme motif for transmembrane electron transport conserved in a yeast iron reductase and the human NADPH oxidase," Journal of Biological Chemistry, vol. 271, no. 49, pp. 31021-31024, 1996.

[41] T. Nakashima, T. Iwashita, T. Fujita et al., "A prodigiosin analogue inactivates NADPH oxidase in macrophage cells by inhibiting assembly of p47phox and Rac," Journal of Biochemistry, vol. 143, no. 1, pp. 107-115, 2008.

[42] A. L. Wang, Z. Li, M. Yuan, A. C. H. Yu, X. Zhu, and M. O. M. Tso, "Sinomenine inhibits activation of rat retinal microglia induced by advanced glycation end products," International Immunopharmacology, vol. 7, no. 12, pp. 1552-1558, 2007.

[43] F. D. Oakley, R. L. Smith, and J. F. Engelhardt, "Lipid rafts and caveolin- 1 coordinate interleukin- $1 \beta$ (IL-1 $\beta$ )-dependent activation of $\mathrm{NF} \kappa \mathrm{B}$ by controlling endocytosis of Nox 2 and IL- $1 \beta$ receptor 1 from the plasma membrane," Journal of Biological Chemistry, vol. 284, no. 48, pp. 33255-33264, 2009.

[44] F. Vilhardt and B. Van Deurs, "The phagocyte NADPH oxidase depends on cholesterol-enriched membrane microdomains for assembly," EMBO Journal, vol. 23, no. 4, pp. 739-748, 2004.

[45] G. Lotocki, O. F. Alonso, W. D. Dietrich, and R. W. Keane, "Tumor necrosis factor receptor 1 and its signaling intermediates are recruited to lipid rafts in the traumatized brain," Journal of Neuroscience, vol. 24, no. 49, pp. 11010-11016, 2004.
[46] R. C. M. Siow and G. E. Mann, "Dietary isoflavones and vascular protection: activation of cellular antioxidant defenses by SERMs or hormesis?" Molecular Aspects of Medicine, vol. 31, no. 6, pp. 468-477, 2010.

[47] A. J. Vargas and R. Burd, "Hormesis and synergy: pathways and mechanisms of quercetin in cancer prevention and management," Nutrition Reviews, vol. 68, no. 7, pp. 418-428, 2010.

[48] V. Calabrese, C. Cornelius, A. Trovato-Salinaro et al., "The hormetic role of dietary antioxidants in free radical-related diseases," Current Pharmaceutical Design, vol. 16, no. 7, pp. 877-883, 2010.

[49] T. G. Son, S. Camandola, and M. P. Mattson, "Hormetic dietary phytochemicals," NeuroMolecular Medicine, vol. 10, no. 4, pp. 236-246, 2008.

[50] B. J. Nichols, "GM1-containing lipid rafts are depleted within clathrin-coated pits," Current Biology, vol. 13, no. 8, pp. 686690, 2003.

[51] B. Yang and V. Rizzo, "TNF- $\alpha$ potentiates protein-tyrosine nitration through activation of NADPH oxidase and eNOS localized in membrane rafts and caveolae of bovine aortic endothelial cells," American Journal of Physiology, vol. 292, no. 2, pp. H954-H962, 2007.

[52] B. M. Barth, S. J. Gustafson, M. M. Young et al., "Inhibition of NADPH oxidase by glucosylceramide confers chemoresistance," Cancer Biology and Therapy, vol. 10, no. 11, pp. 11261136, 2010.

[53] R. A. Siddiqui, K. A. Harvey, G. P. Zaloga, and W. Stillwell, "Modulation of lipid rafts by $\Omega-3$ fatty acids in inflammation and cancer: implications for use of lipids during nutrition support," Nutrition in Clinical Practice, vol. 22, no. 1, pp. 7488, 2007.

[54] R. S. Chapkin, N. Wang, Y. Y. Fan, J. R. Lupton, and I. A. Prior, "Docosahexaenoic acid alters the size and distribution of cell surface microdomains," Biochimica et Biophysica Acta, vol. 1778, no. 2, pp. 466-471, 2008.

[55] J. P. E. Spencer, "The impact of flavonoids on memory: physiological and molecular considerations," Chemical Society Reviews, vol. 38, no. 4, pp. 1152-1161, 2009.

[56] F. C. Lau, B. Shukitt-Hale, and J. A. Joseph, "The beneficial effects of fruit polyphenols on brain aging," Neurobiology of Aging, vol. 26, pp. S128-S132, 2005. 


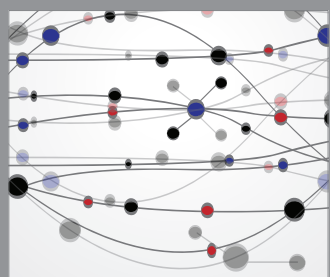

The Scientific World Journal
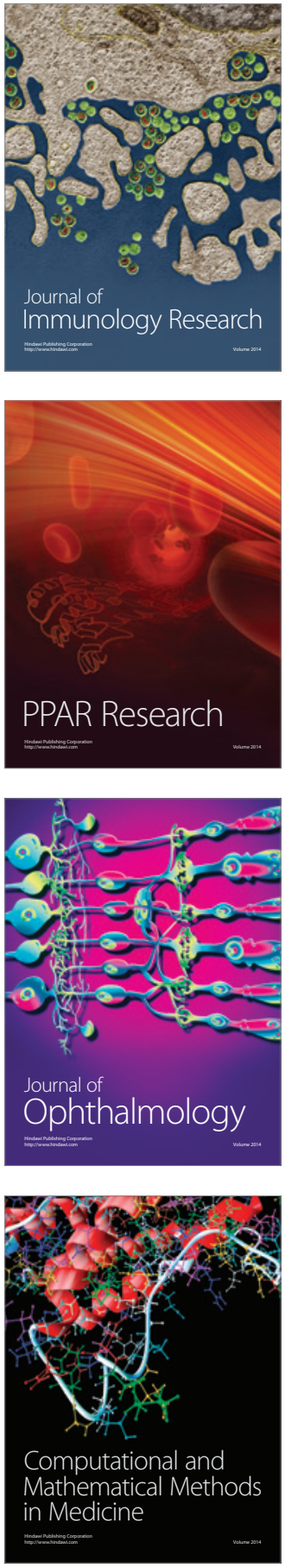

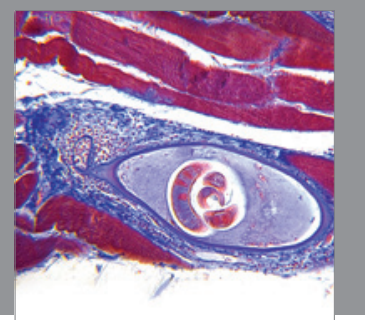

Gastroenterology

Research and Practice
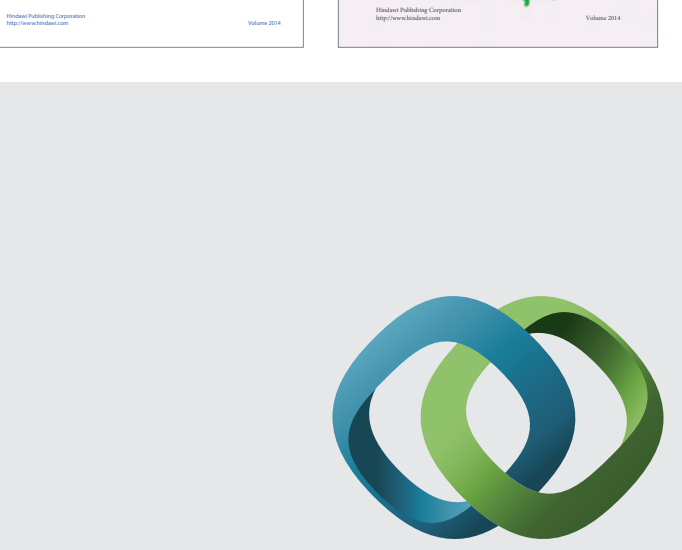

\section{Hindawi}

Submit your manuscripts at

http://www.hindawi.com
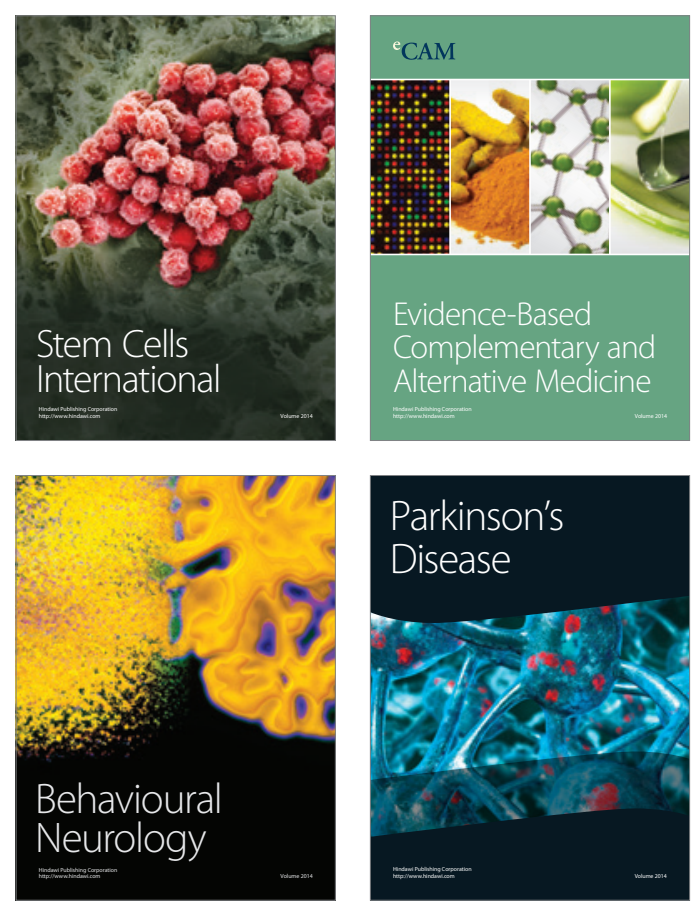

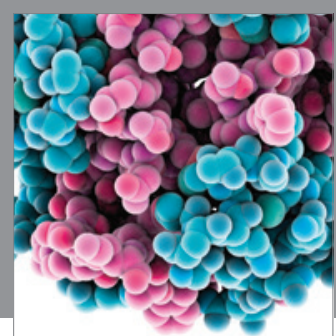

Journal of
Diabetes Research

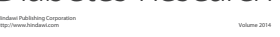

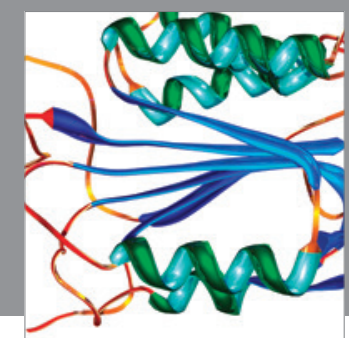

Disease Markers
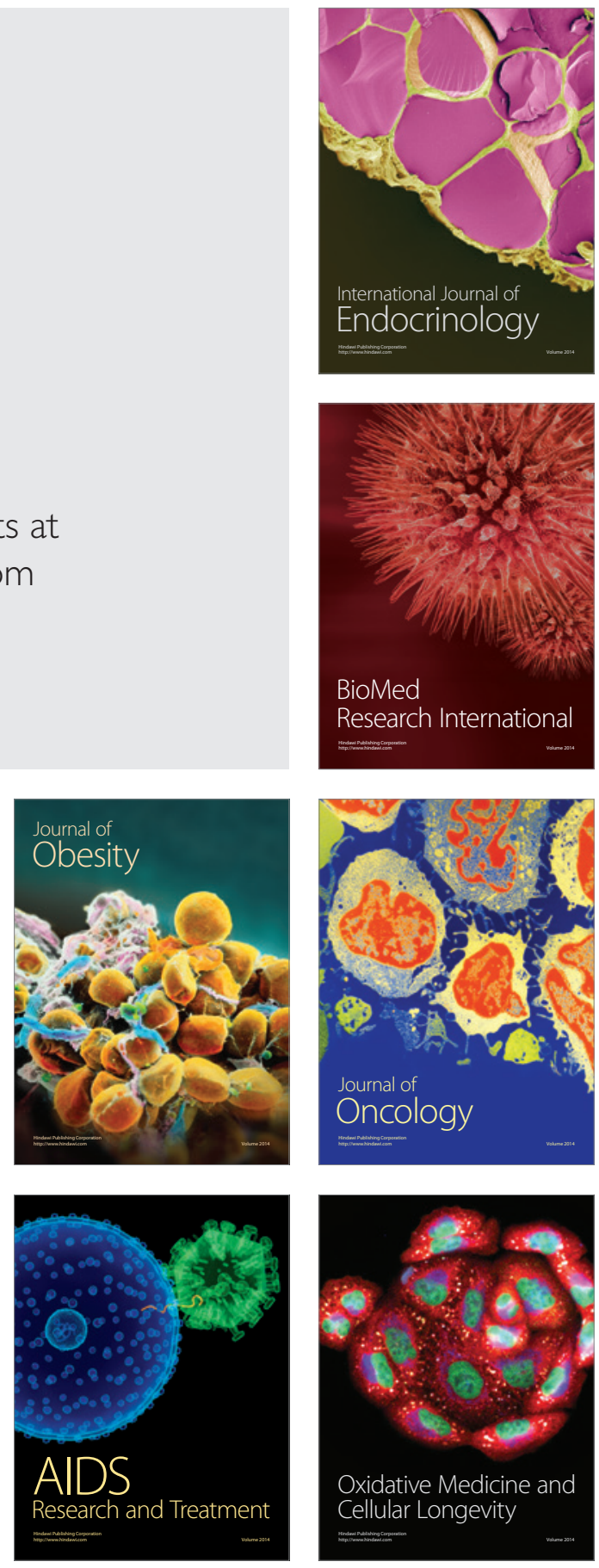